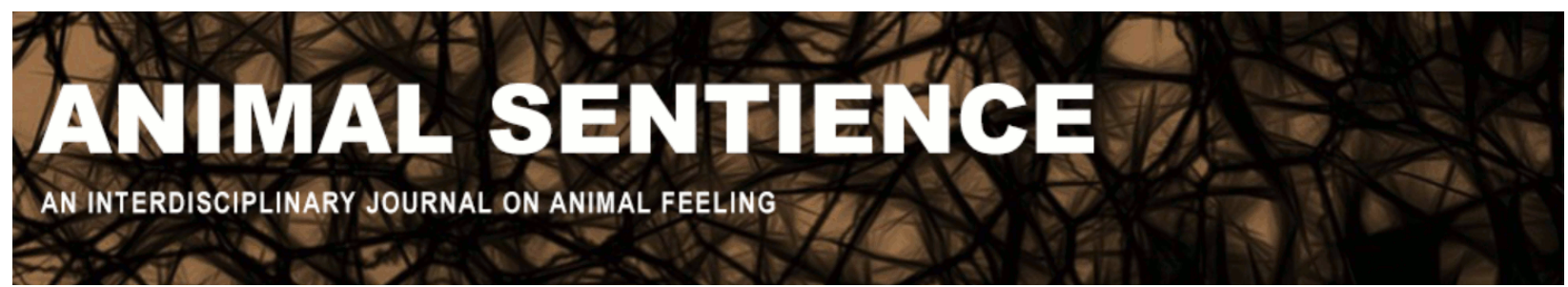

Mather, Jennifer (2019) What is in an octopus's mind?. Animal Sentience 26(1) DOI: $10.51291 / 2377-7478.1370$

Date of submission: 2018-09-12

Date of acceptance: 2019-05-06

(c) (i)


Call for Commentary: Animal Sentience publishes Open Peer Commentary on all accepted target articles. Target articles are peer-reviewed. Commentaries are editorially reviewed. There are submitted commentaries as well as invited commentaries. Commentaries appear as soon as they have been reviewed, revised and accepted. Target article authors may respond to their commentaries individually or in a joint response to multiple commentaries.

INSTRUCTIONS FOR COMMENTATORS

\title{
What is in an octopus's mind?
}

\author{
Jennifer Mather \\ Department of Psychology \\ University of Lethbridge
}

\begin{abstract}
It is difficult to imagine what an animal as different from us as the octopus 'thinks', but we can make some progress. In the Umwelt or perceptual world of an octopus, what the lateralized monocular eyes perceive is not color but the plane of polarization of light. Information is processed by a bilateral brain but manipulation is done by a radially symmetrical set of eight arms. Octopuses do not self-monitor by vision. Their skin pattern system, used for excellent camouflage, is open loop. The output of the motor system of the eight arms is organized at several levels - brain, intrabrachial commissure and local brachial ganglia. Octopuses may be motivated by a combination of fear and exploration. Several actions - a head bob for motion parallax, a 'Passing Cloud' skin display to startle prey, and particularly exploration by their arms - demonstrate the presence of a controlling mind, motivated to gather information. Yet most octopuses are solitary and many are cannibalistic, so they must always be on guard, even against conspecifics. The actions of octopuses can be domain general, with flexible problem-solving strategies, enabling them to survive "by their wits" in a challenging and variable environment.
\end{abstract}

Keywords: octopus, Umwelt, arm control, exploration, mind

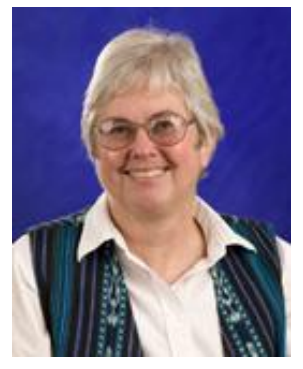

Jennifer Mather is Professor in the Department of Psychology, University of Lethbridge. She has published many articles on cephalopod behavior and intelligence and is regarded as an authority on ethics with regard to cephalopods. Website 
It is difficult to imagine the minds of other animals, as Nagel (1974) emphasized when discussing what it might be like to be a bat. This problem is larger when one thinks of the octopuses, with eight arms, a separate skin display system and 3/5 of their nervous system in the arms. Theorists have speculated about octopuses' domain-general cognition (Vitti, 2013), representation of the spatial world (Grasso, 2014), monitoring of self (Godfrey Smith, 2016), and their putative lack of a single locus of consciousness (Carls-Diamante, 2017). Yet we do have enough information to evaluate how octopuses might have a unity behind the diversity when organizing their world. This target article adopts an ecological approach (Dukas, 1998) based on von Uexcull, von Uexcull \& O'Neill's (1934) principles of the Umwelt and the Wirkwelt, the individual's perceptual and action worlds. I first describe octopuses' sense of self and of the world around them; the functions of their skin patterning and arm motor control systems; and how octopuses may be guided by two motivational bases, exploration and fear. Based on the fact that they explore to acquire information, calculate what they can do with the world around them and use flexible problem-solving strategies when threatened by predators or conspecifics, I argue that octopuses have a mind.

\section{What is the world of the octopus like?}

\section{1.a. What does an octopus know about itself?}

Understanding octopus cognition and self-awareness is complicated by the fact that octopuses do not have nervous systems as centralized as those of vertebrates (Mather \& Dickel, 2017). While their brain-body ratio is higher than that of many vertebrates (Packard, 1972), 3/5 of the neurons of octopuses are not in their brain but out in their arms, guiding complex actions of a muscular hydrostatic movement system (Kier \& Smith, 1985). Although they have an excellent lens eye comparable to that of 'higher' vertebrates, vision does not dominate their perception as much as it does in humans. Their very sophisticated skin display system (Messenger, 2001) does not seem to have the self-monitoring that we expect from motor output.

All of this leads to what we might call a different 'way of being' in the world. The cephalopod central brain, which is large even by vertebrate standards (Packard, 1972), has about 40 lobes. The vertical lobe can be considered to contain a true learning and memory system. Like the vertebrate brain, it is well-organized neurally (Hochner \& Shomrat, 2014). The vertical lobe is not the site of storage of long-term memory, but instead an organizing area. Sensory input feeds into it in parallel; it modulates short-term memory and encodes long-term memory. Both of these memory traces are stored outside the lobe, however, and actions are programmed in the sub-esophageal areas of the brain. Shigeno, Andrews, Ponte \& Fiorito (2018) have discussed cephalopod brain areas that would parallel the functional allocation seen in vertebrates. With this control circuitry, octopuses can perform the operations suggested by Emery \& Clayton (2004) as indicative of cognitive ability in mammals and birds - flexibility, causal reasoning, prospection and imagination (Mather \& Dickel, 2017). Alongside this cognitive circuitry, however, there are different nervous system areas that must channel and limit octopus cognition. 


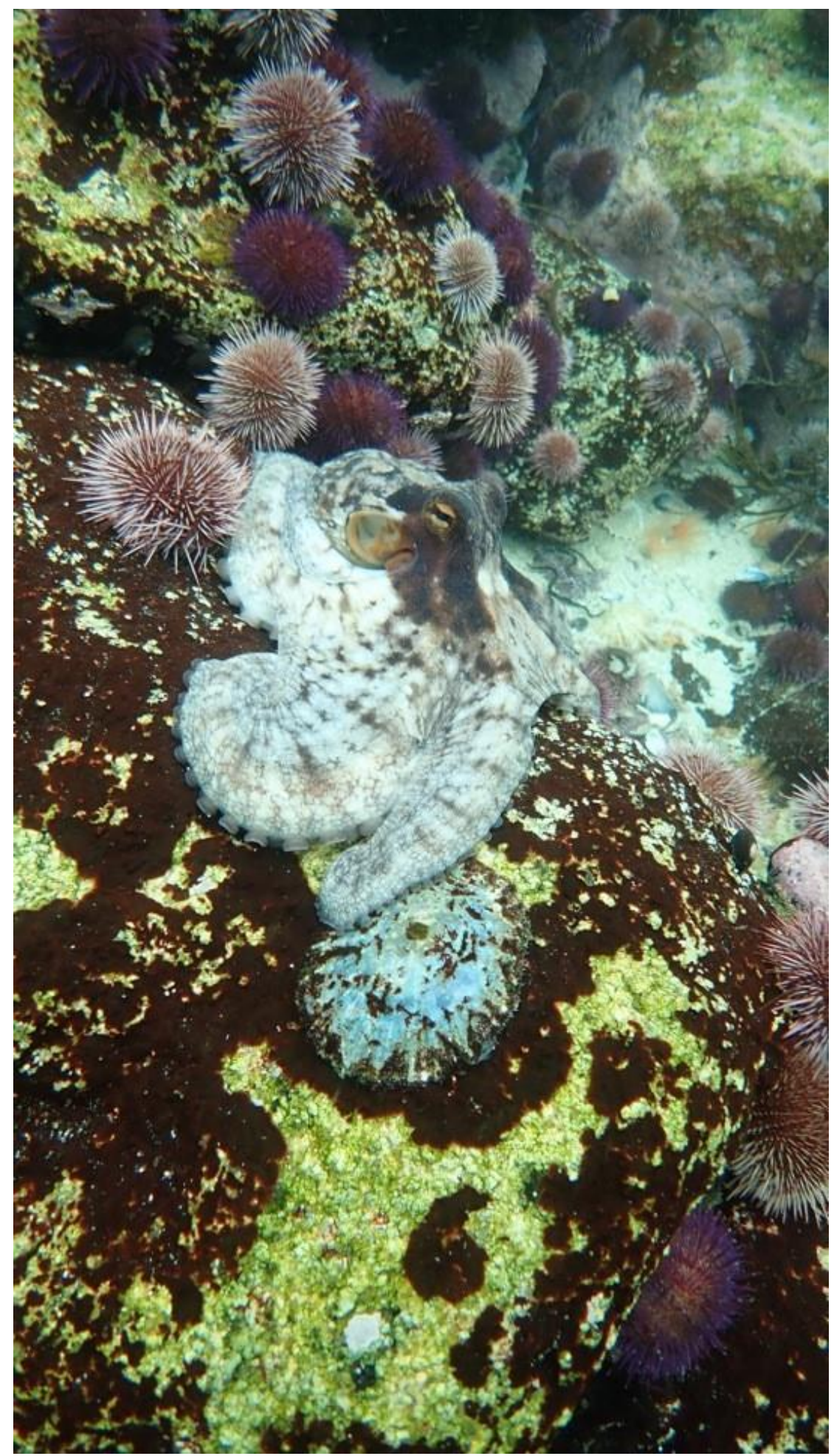

Figure 1: This picture of an octopus shows the eight flexible arms spread around it with the head, including the lateral eye, showing brown above, and the inflated mantle to its posterior. This shows it to be a Cephalopod, or 'head-foot', though they are not feet, but arms. (Photo by Craig Foster) 
1.a.1. Skin pattern production. Octopuses have a complex appearance system, not pigment cells but a whole system. Chromatophores are elastic sacs, producing yellow, red or brown color when they are pulled out by muscles whose motor neurons are in the chromatophore lobes of the brain, with their axons spread across all the areas of the skin in a spatial array (Messenger, 2001). When the chromatophores are contracted, reflective cells return the wavelengths of light that are present in the environment, giving good camouflage at low light levels (Buresch et al., 2015). The chromatophore patterns generate excellent colored camouflage (see Chiao, Chubb \& Hanlon, 2015, for cuttlefish), despite the fact that cephalopods are color blind (Figure 1). These patterns do not stand alone, as the skin surface can be raised in papillae which give it texture (Gonzales-Bellido, Scaros, Hanlon \& Wardill, 2018); this is well-studied in cuttlefish but likewise present in octopuses. Postures, particularly of the arms but also of the body, imitate features of the environment or even other animals, further contributing to camouflage. Josef, Amodio, Fiorito \& Shashar (2012) used image analysis algorithms and found that this octopus camouflage was not due to a general background matching but rather imitation of particular key features in the immediate surroundings.

The skin display system is mostly used as camouflage in octopuses, but it is also used in other situations, as likewise observed in cuttlefish and squid (Hanlon \& Messenger, 2018). Although the semi-automatic camouflage function is better known, cephalopods use their skin for several communicative purposes. For example, several species of octopus and cuttlefish use a display called 'Passing Cloud' expanding and contracting chromatophores so that a cloud-shaped figure appears to move along the skin surface in an anterior direction (Mather \& Mather, 2004). This apparent movement, aimed at startling potential prey, allows the octopus to 'move' while remaining stationary, so that the prey's image on the octopus's retina does not slip. Another communicative pattern is the black and white contrasting startle display produced in response to a threat from a predator. In cuttlefish and squid, this takes the form of eye spots (Langridge, Broom \& Osorio, 2007; Mather, 2010); in octopuses, it takes the form of web spread with contrasting dark around the eyes (Mather \& Alupay, 2016).

Although few octopus species use the skin system during courtship, Abdopus aculeatus males form black and white stripes on their skin, displaying them to rival males and guarded females (Huffard, Caldwell \& Boneka, 2008, 2010). Sexual skin displays are much more developed in cuttlefish (Hall \& Hanlon, 2002) and squid (Mather, 2016). Yet this complicated and adaptive system seems to be open loop and again not centrally monitored. Octopuses probably need the powerful deception of camouflage because evolutionarily they have lost their protective shell, protected particularly from the visually dominant bony fishes only by their appearance and behavior (Packard, 1972).

The circuitry starts with high acuity vision, but with only one photopigment in the eyes, octopuses can only distinguish light's plane of polarization, not its wavelength. Stimulation of the massive optic lobe, immediately connected to the eyes, reveals that skin output patterns are produced there (Liu \& Chiao, 2017), but without the somatotopic organization found in vertebrates. Godfrey-Smith (2016) has suggested that cephalopod brains lack reafference copy of their actions (the internal feedback loops duplicating action commands that help vertebrate brains monitor their motor output). This is not quite correct for the skin patterns, as the commands pass from the optic to the lateral basal lobes directly and also via the peduncle lobes, both with feedback loops (Williamson \& Chrachri, 2004). Still, the motor neurons of the chromatophore lobes generate no feedback, so there is no internal copy of the 
final output. Despite this, cuttlefish camouflage closely matches the color sensitivity of vertebrate receivers' eyes (Chiao, Wickiser, Allen, Genter \& Hanlon, 2011; see Figure 2).

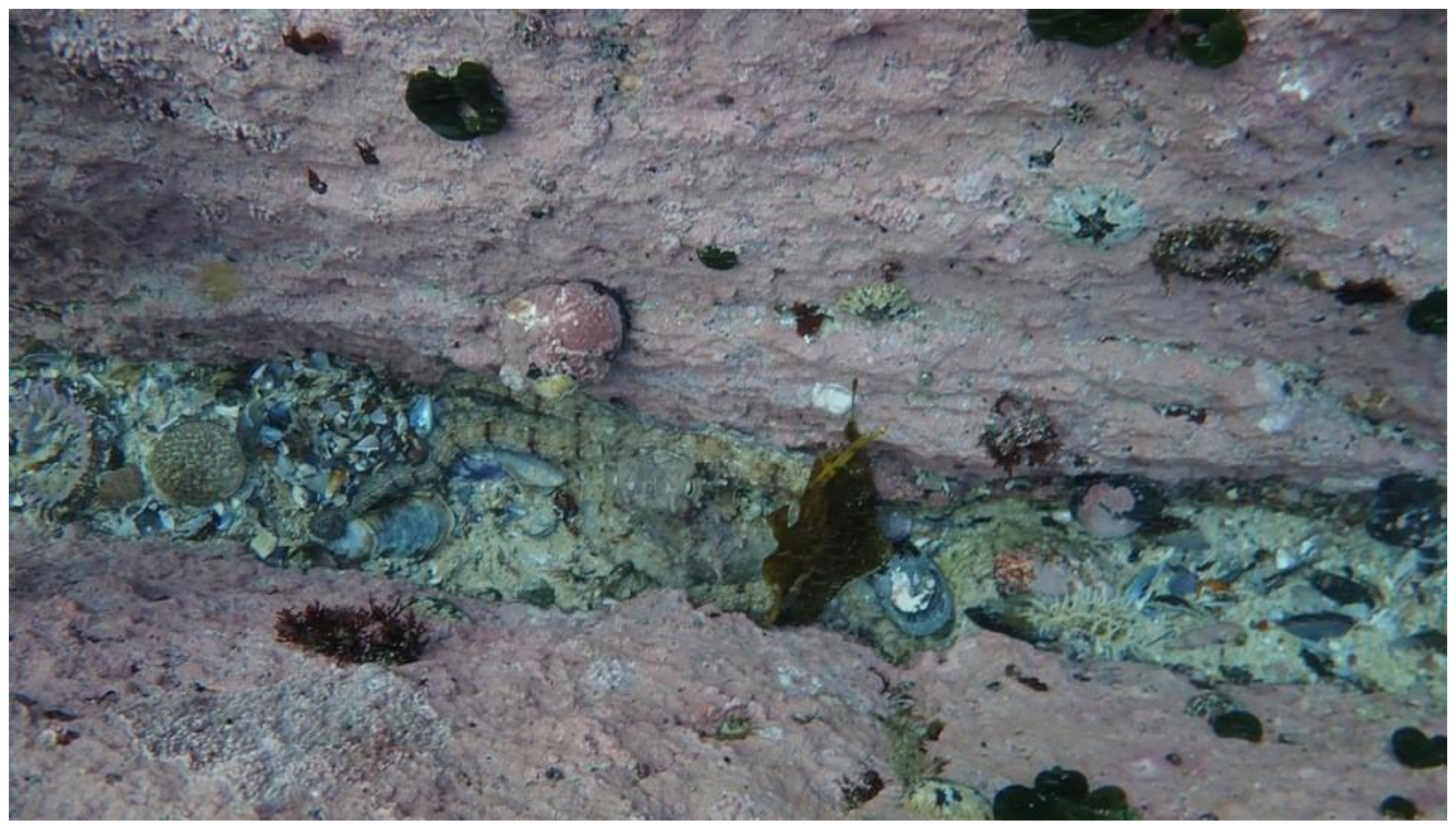

Figure 2: This octopus is producing excellent camouflage tuned to vertebrate eyes. (Photo by $\underline{\text { Craig Foster) }}$

1.a.2. Arm movement. The central-peripheral balance of control is complex for the movement of the eight octopus arms. Three fifths of octopus neurons are in the arms, but it is not clear to what extent arm actions are centrally monitored. One or two rows of adhesive suckers line the ventral surface of octopus arms; these have many tactile and chemical receptors in addition to being powerful attachment structures (Kier \& Smith, 2002). A nerve cord runs along each arm as a sequence of brachial ganglia (see Grasso, 2014, Figure 5.2), with neighboring ones serially connected. A sucker ganglion above each sucker is connected only to its own brachial ganglion. Each arm is a muscular hydrostat movement system, with an almost unlimited number of degrees of freedom for action (Kier \& Smith, 1985). For any movement, some of the muscles of the arm stiffen to make support structures and others articulate against them to cause motion; this combination may be too complex for central programming and monitoring. At the base of the brachial nerve cords, an interbrachial commissure links all the cords, but unfortunately, its function has been little investigated (see ten Cate, 1928, see Figure 3).

What representation of arm position and sensory feedback is present in the brain? Zullo, Sumbre, Agnisola, Flash \& Hochner (2009) stimulated the control area of the basal lobes of Octopus vulgaris and were not able to find the expected somatotopic representation of the motoneurons. From this they concluded that the octopus brain was not able to monitor the position and state of the arm and that the lower level control and monitoring of arm actions was allocated to the chains of ganglia. Since a somatotopic organization was not found in the optic lobe either (Liu \& Chiao, 2017), there may simply be a 'mosaic' organization in both. Grasso (2014) carried the assumption of levels of control even further. He concluded 
that the octopus had two brains: the brachial plexus had the capacity for somewhat autonomous behavior and it formed a representation as well as a control system for the arms. On this basis, Carls-Diamante (2017) speculated that octopuses might have two loci of consciousness. The conclusion from Grasso's (2014) reconstruction was that the brain gave only general commands to the arms and that it "did not know what the arms were doing". Yet the vertebrate movement system, with which it is inevitably contrasted, is not rigidly controlled and monitored centrally either. Initiation of locomotion is central (Jordan, Brownstone \& Noga, 1998), but the pattern output circuitry is in the spinal cord (McCrea, 2001) aided by the reflex responsiveness of the muscles. A similar central-peripheral combination may also be present in the octopus.

On the basis of this physical arrangement, Hochner (2012) concluded that the many degrees of freedom were constrained to simpler stereotyped arm movements called motor primitives, especially bend propagation along the arm and formation of pseudo-joints as places of articulation. These actions would be generated by the interaction of the brachial ganglia, combined as units and unmonitored by the brain. However, the testing situation for the assessment of these basic actions was itself fairly stereotyped. When Richter, Hochner \& Kuba (2015) challenged octopuses to extend an arm through a hole in a perspex panel, they did not use actions based on these motor primitives. They either used a straight extension through the hole or extended the arm partly through the hole and waved the distal portion through the water. Not only were arm actions variable, but octopuses could also monitor them centrally to some extent. $O$. vulgaris learned to direct an arm in a maze on the basis of visual cues (Gutnick, Byrne, Hochner \& Kuba, 2011), or kinesthetic or tactile ones (Kuba, personal communication). Visual information was not available for actions of the octopus mouth area; non-visual kinesthetic cues from the arms were used by octopuses to orient clams under the web in different positions for pulling open or penetrating their shell, using different techniques (Anderson \& Mather, 2007, for Enteroctopus dofleini). Octopuses also self-monitor arms in some situations. When an arm is damaged, octopuses tend the wound (Alupay, Hadjilosolomou \& Crook 2014), moving the affected area to the mouth and evaluating the damage, protecting it and running the suckers of other arms along it, actions which must have been centrally coordinated.

Perhaps cephalopod self-monitoring is not mainly visual, as chemical cues from the skin of an octopus's own arm partially block self-grasping by the suckers (Nesher, Levy, Grasso \& Hochner, 2014). Octopuses did not succeed in recognizing themselves in even a partial test of Gallup's (1995) mirror self-recognition task (Mather, Carere, Fiorito \& Anderson, 2018). $O$. vulgaris perceived this visual feedback as an anomalous situation and not a view of a conspecific; they made more mantle-up challenge displays to conspecifics and more Passing Cloud displays to the mirror. Many other species, such as grey parrots (Pepperberg, Garcia, Jackson \& Marconi, 1995) also fail to 'pass' the mirror test and yet can use visual information to direct themselves in space. Similarly, octopuses can visually distinguish between two humans (Anderson, Mather, Monette \& Zimsen, 2010). Their use of vision might be otherdirected rather than self-directed. 


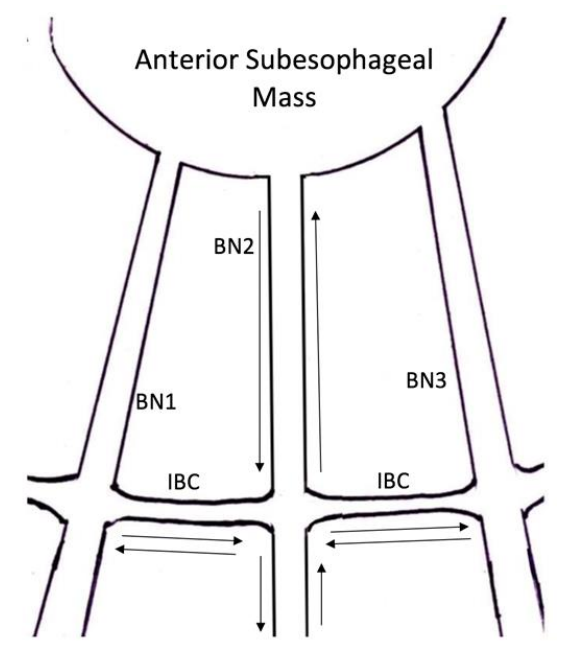

Figure 3a: This diagram shows routes of distributed motor output from the octopus brain toward, along, and between the arms, as represented in some of the eight arms. BN stands for brachial nerve (of each arm), and IBC stands for the interbrachial commissure between arms.

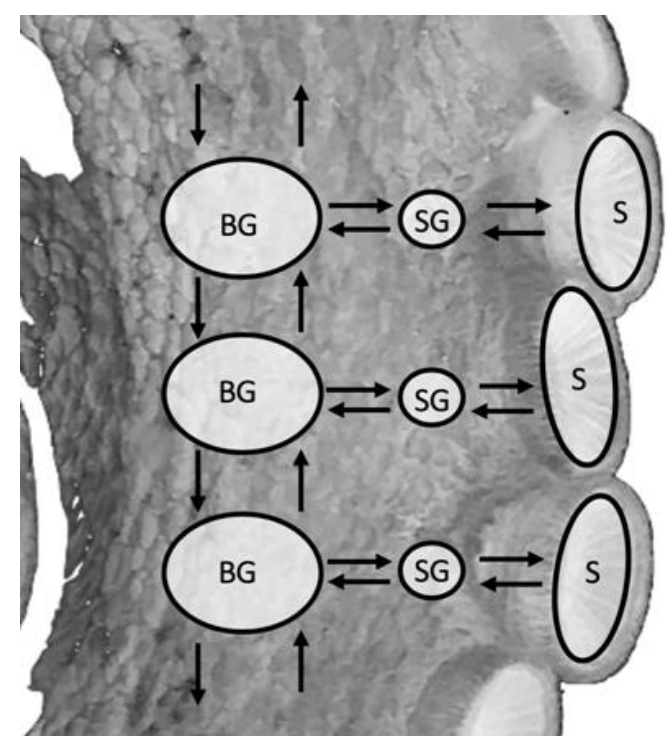

Figure 3b: This diagram shows the circuitry of the routes of control of a few of the neural chains of ganglia running along the octopus arm, superimposed on a side-view of the arm itself. BG stands for brachial ganglion, SG stands for sucker ganglion, and S stands for the sucker.

Octopuses' arm actions are often part of coordinated activities with other parts of the body. If one of these arms has been lost and regenerated but is too short enough to contact a target effectively, the animal does not attempt to use it; its place in the 'slapping' sequence (Mather, 1992) toward a threatening fish is taken by a more ventral arm (personal observation of Abdopus sp.). Arm positions supplement the skin color and papillae erection (GonzalesBellido et al., 2018) that accomplish camouflage by masquerade and mimicry (again studied in detail in cuttlefish, Chiao et al., 2015). A coordinated spread-arm position and web extension (Mather \& Alupay, 2016) produce the enveloping Web-Over posture forming a sac that covers a portion of the landscape. Within this umbrella, octopuses search with distal arms for the small prey items they have trapped. Yet arm cooperation is variable, as octopuses sometimes use several arms independently for chemotactile search in several 
unseen locations (Mather, 1991a). They can also extend an arm to block one side entrance to a burrow before entering a main one to capture hidden prey (personal observation, Abdopus sp.), or coordinate the arms to dig in sand for bivalve prey.

This variable allocation echoes Godfrey-Smith's (2016) suggestion that octopuses have a mixture of loci of control - sometimes the brain, sometimes along the interbrachial commissure and sometimes through coordination of local brachial ganglia. Japyassu \& Laland (2017) describe this strategy as "outsourcing of processing power from the centre to the periphery of the nervous system" (p. 387). It is stimulated by the complexity of the muscular hydrostat movement system (Kier \& Smith, 1985). The prey-finding strategies of cephalopods are always flexible (see Hanlon \& Messenger, 1996) and adapted to the species and situation. Perhaps guided by chemical cues, octopuses can extend an arm along a crevice or use water jets from the funnel to 'blow' sand off a concealed crab. Finally, casual observations of all three cephalopod groups have yielded reports that they can extend one arm or a tentacle, retract the chromatophores at the tip so it becomes white, and 'wiggle' it as a lure for attracting curious mobile prey. This is an obvious example of flexibility and planning in predation, using body positions, chromatophore control and arm actions together. Arm actions must be partly monitored at the local level, yet some are centrally planned and coordinated.

Regardless of the locus of control and monitoring, the manipulative ability of eight sucker-lined arms must have contributed to the development of octopus intelligence. At a local level, suckers can grasp items or the substrate with a strong grip (Kier \& Smith, 2002). Early casual studies have reported that $O$. vulgaris had a pulling force of ten times its weight (Dilly, Nixon \& Packard, 1964). Suckers can also fold toward the center to make a pincer grasp so precise that an octopus can use fine manipulation in situations not found in nature, such as untying knots in surgical silk, pulling apart a floating thermometer and taking lids off jars (Fiorito, von Planta \& Scotto, 1990; Anderson \& Mather, 2010). Female octopuses use the stalks of the proximal suckers as bobbins to weave together the stems of eggs and form them into large interwoven strings, which are then suspended from the upper area of the shelter. Grasso (2008) found that a few sucker-arm segments of an octopus attempting to remove a cap from a base could exert different but coordinated local actions, grasping several areas and extending small arm segments.

The octopus has two different distributions of motor control, bilateral for the brain and radial for the arms (see Figure 4). Part of the problem in understanding octopus movement control is that we do not know how a radially organized output system is controlled; another part is that we do not understand how the system responds to this bilateral-radial mixture. Octopuses make movement 'decisions', selecting specific arms for particular actions or combining them as different components of coordinated ones. Arms are equipotential in that each one in this radial array can perform many different actions (Mather, 1998), but specific arms are more likely to do different behaviours, probably in response to bilateral output. When crawling, octopuses allocate their four posterior arms to pushing along the substrate and their four anterior ones to exploring the area ahead. However, they do not always move forward, so the arms allocated for crawling might be the left four, for instance, if the animal is moving rightward, a clear flexibility of organization around the radial array. Carls-Diamante (2017) has suggested that the motor centers of the brain might thus 
only need to activate a general motor program setting direction; the mechanical properties of the arms then carry out the flexible local details. According to ten Cate (1928), however, coordination around the commissure is more likely.

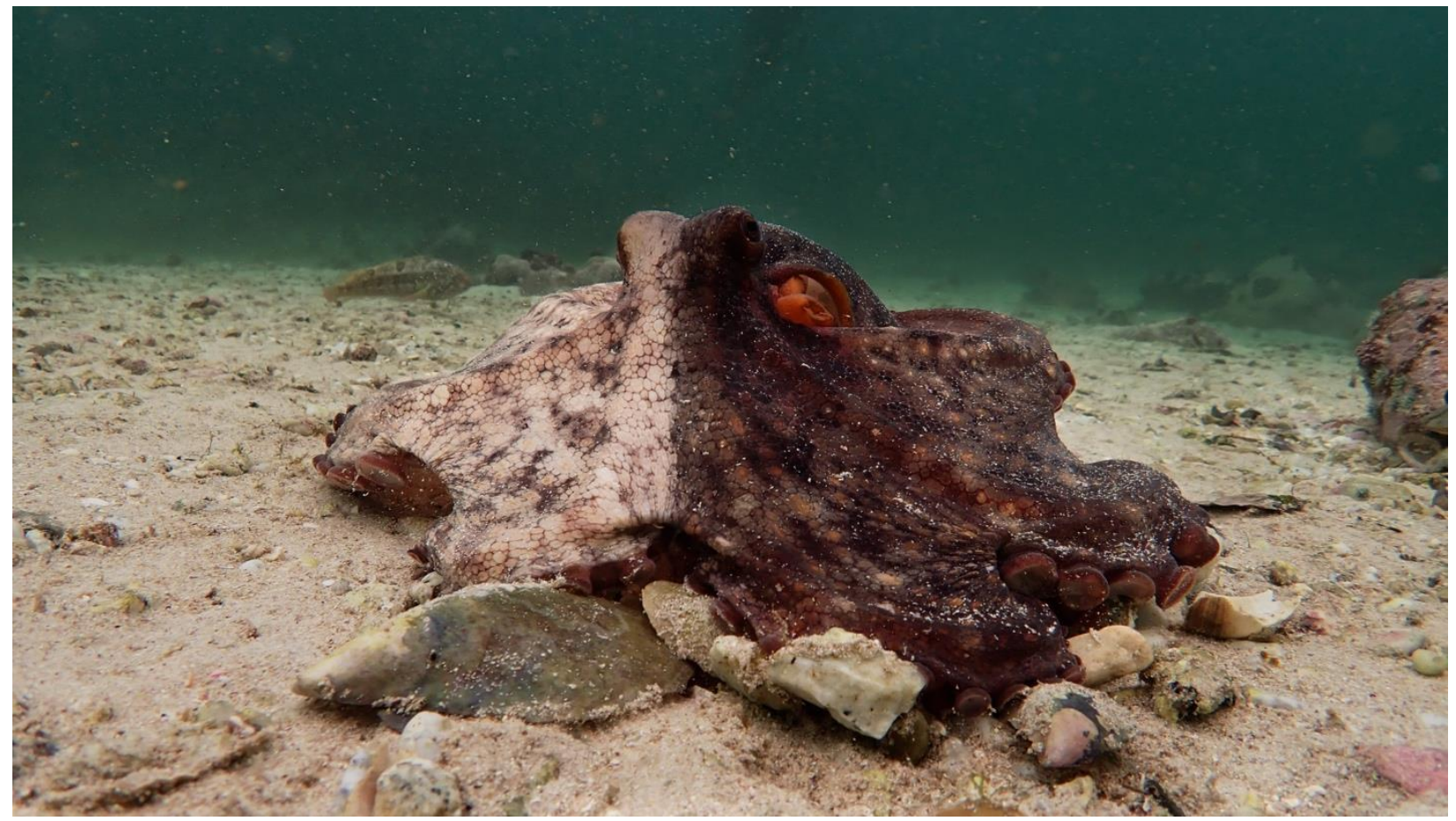

Figure 4: This octopus is doing a display called Half and Half, in which chromatophores are expanded over all of one side of the animal (dark) and contracted (pale) on the other side. It has no known function, but shows us how the octopus is bilaterally symmetrical. (Photo by Craig Foster)

Arms 1-left and 1-right (and secondarily, 2-left and 2-right) are more likely to be used for exploration. Byrne, Kuba, Meisel, Greibel \& Mather (2006a) found that individual O. vulgaris each has one of these as a 'preferred' arm for single-arm exploration, probably in response to eye-brain control. When a second arm is recruited to assist with the action, it is often the 'next-door' one, perhaps as a result of commands extending around the interbrachial commissure. On the other hand, octopus arm use is heavily influenced by allocation of attention to one of the lateralized eyes (Byrne, Kuba, Meisel, Greibel \& Mather, 2006b), a central influence. We might hope to compare such coordination to that of the radial echinoderms, who have pentameral symmetry. However, they have underlying bilateral tendencies (Ji, Wu, Zhao \& Lv, 2012), based on the larval bilaterality, so perhaps they also use a mixture of the two types of control.

The flexibility of arm use not only extends to choices, but different arms perform different actions in coordinated behavior, not as stereotyped motor primitive units. The arm 'slap' at a scavenging fish (Mather, 1992) involves mostly the dorsal four arms, with the posterior four holding on to the substrate to brace the animal. An octopus unscrewing a lid from a jar can use several arms to hold the jar (Anderson \& Mather, 2010), while one or two turn the lid. Different individuals perform this behavior using different arms and actions, suggesting that action choices are far from being an automatic combination of stereotyped units. In the difficult task of reaching through a small hole, individual 0 . vulgaris choose one of two different movement strategies (Richter et al., 2015), again suggesting that these 
actions are not stereotyped across individuals. Grasso (2008) also found that different arms were allocated to different parts of the coordinated actions. Interestingly, gait analysis of octopus 'walking' (Levy, Flash \& Hochner, 2015) turned up no pattern at all in arm use sequences, quite unlike those in vertebrates and arthropods. How can you have order without predictability? Perhaps it involved feedback and 'decisions' communicated around the commissure (ten Cate, 1928). The modal direction relative to straight ahead of octopuses when walking was 45 degrees to one side or the other, so the monocular octopus was choosing visual movement guidance by one eye and proceeding under its influence. In a different context, the small Abdopus sometimes combines two differently motivated response sets when walking in a threatening open-area situation. They hold several arms in Camouflaging postures and push with only some of them, usually the posterior pair (Huffard, 2006). Choosing and coordinating arm actions must be under the command of a central controller, yet with the use of peripheral subsystems.

An intriguing set of observations from the field suggests that octopuses not only manipulate their environment: they also anticipate what is needed for the future. Several individuals of Amphioctopus marginatus have been observed to dig separated coconut halves out of the sandy mud and carry them, stacked under their arms, across the substrate (Finn, Tregenza \& Norman, 2009). After travel of up to $20 \mathrm{~m}$, they rearrange the halves as shelter and hide inside them, holding them together from the inside. Such planning is probably common in octopuses but not always easy to recognize.

\section{1.b. How do octopuses extract information about the environment?}

Examining how an octopus 'thinks' demands that we use the approach of von Uexcull et al. (1934) and evaluate their Umwelt, or sensory and perceptual world. Octopuses live in water, which transmits mechanical and chemical information very effectively, although little research has been done on these areas of sensory perception and communication in cephalopods. The ocean is also dominated by the bony fishes. As predators, prey and companions (Packard, 1972), they form an important part of the octopus's environment. Fish provide what Gibson (1979) would call affordances, or clues in the environment that 'direct' particular behaviours (see Withagen, de Poel, Araujo \& Pepping, 2012). Hochner (2012) advanced the idea of environmental specification as 'embodied cognition', although his exposition did not move beyond the arm control system; see Japyassu \& Laland (2017) for the 'embodiment' of the web-building spiders in their webs. However, Hochner (2012) pointed out the necessity of understanding the mechanical and sensory systems as well as how they interact with the specific environment. These principles are also discussed by Godfrey-Smith (2016). We cannot evaluate how octopuses think without taking their ecological context into consideration. For this we need both the control of laboratory experiments and the ecological validity of field observations (Mather \& Kuba, 2018).

One notable area in which to use the Umwelt approach is the evaluation of visual information by octopuses (see Gleadall \& Shashar, 2004). The similarity of cephalopod and mammalian eyes is often held up as an excellent example of convergent evolution, yet there are also some important differences. With only one photopigment, nearly all cephalopods are color-blind, even though their skin camouflage matches the perceptual ability of the vertebrate fishes (Chiao et al., 2011). Since color information is not available to the cephalopods, camouflage programming must have been shaped by selection and is not available for assessment by the octopus itself. In contrast, cephalopods can discriminate the 
plane of polarization of light (Mäthger, Shashar \& Hanlon, 2009) and use it to navigate (Cartron, Darmaillacq, Jozet-Alves, Shashar \& Dickel, 2012) and to aid in viewing in turbid water (Cartron et al., 2013). Water distorts light polarization, and there is some polarization reflectance in selected cephalopod skin areas. This dimension too is available for the animals to use for communication. Water also filters out most of the red end of the visual spectrum of light, so as depth increases this restricted spectral range, color information becomes less useful. The plane of polarization of light remains informative, however, and sensitivity to this dimension also 'breaks' the reflective camouflage of fish scales and transparent animals. Polarization sensitivity is only beginning to be investigated (Mäthger et al., 2009). The same light may actually create a different sensory world for cephalopods and their fish competitors.

Extensive study of the visual encoding cues and neural organization of $O$. vulgaris (although tested in an ecologically inappropriate context) has provided a clear idea of visual shape discrimination capacity, presumably under some sort of central control (Sutherland, 1957; Wells, 1978). In small laboratory tanks at Naples, octopuses learned to come out of their shelters and were rewarded for touching one shape and given a small shock for touching the other. Researchers first found that vertical and horizontal extent was an important cue for figure discrimination. However, octopuses learned subsequent contrasts based on general shape (circles and squares), size, edge-area ratio and even directionality of reduplicated patterns. The octopuses did not have a simple shape assessment system; rather they learned to use the cues that were relevant for a particular comparison, for which they were described as a 'learning machine' by Wells (1978). Some cues about the octopuses' learning system came from the fact that they could learn a very difficult discrimination if they were given it in a sequence of finer and finer differences. With two relevant differences between shapes, they learned faster than with only one; but some individuals used one of them and some the other. More recently, researchers have found that cephalopods succeed in a wide array of learning contexts, including reversal (Bublitz, Weinhold, Strobel, Deinhardt \& Hanke, 2017) and episodic-like memory (Jozet-Alves, Bertin \& Clayton, 2013) tasks. Reviewing the many paradigms in which octopuses have succeeded in learning, Zarella, Ponte, Baldascino \& Fiorito (2015) described the octopus as a model of 'biological plasticity'.

Monocular visual control through laterally placed eyes is another aspect of the octopus's Umwelt. Using brain ablation and disconnection techniques, early authors were able to test how they used and stored visual information. Octopuses trained on a discrimination using only one eye were not immediately able to perform it when the stimulus was presented to the other eye, so initial storage was unilateral. By the next day, however, they were able to make the discrimination. So the information had been transferred to the other side of the brain, as also observed in birds (Clayton, 1993). If the commissure between the two brain halves was cut before training, the octopus was not able to transfer to the other side. This showed researchers a different kind of implementation for a bilateral brain. Human bilateral brains have extensive lateralization of function, and recent research has also found physical lateralization in cuttlefish brains (Schnell, Hanlon, Benkada \& Jozet-Alves, 2016): One side is specialized in information used for predation and the other in vigilance; there are also sex differences in these capacities (Jozet-Alves, Moderan \& Dickel, 2008). It may be a general principal that duplication of action in brain halves eventually results in lateral specialization. Squid (Mather, 2016a) and cuttlefish (Brown, Garwood \& Williamson, 2012) can make one skin display pattern to one side and a different one to the other. This brings out 
an obvious parallel with split-brained humans and suggests that Carls-Diamante (2017) may be right in speculating about divided consciousness in octopuses, but on the basis of the same brain duality as in other bilateral brains.

The use of chemical information in most animals is regrettably understudied, and octopuses are not an exception. They have an olfactory organ whose structure has recently been carefully examined (Polese, Bertapelli \& Di Cosmo, 2015); soon we will know more about its function. Field researchers suspect that male octopuses find females by following chemical cues, as visual displays are not common. Prey-finding is a two-step process (Mather, Leite, Anderson \& Wood, 2014). Octopuses first orient visually to habitat where preferred prey are likely; they then locate hidden prey by chemotactile exploration with the arms and suckers. Chemical sensing is hence likely to be important at both the local and global levels. We know so much about the octopuses' visual capacity because we find it easy to study, but it may not prove to be as important to the animals as we believe.

Early researchers, because they did not really understand the octopuses' Umwelt, made a mistaken assumption about their perceptual and cognitive abilities. They tested 0 . vulgaris for whole-body orientation in the world by presenting octopuses with a crab behind a window, then giving the animals access to this prey by a detour through a corridor next to it. The octopuses could not make this detour, so Wells (1978) concluded that they could not monitor their position in the environment - although he did report that Walker, Longo \& Bitterman (1970) succeeded in teaching octopuses a T-maze task, and that they could follow one of the maze walls to the reward. Mather (1991a) tracked octopuses in the field, where they had acquired much more spatial information, moving out from their sheltered homes and returning to them. They could recall where they had hunted in previous days and used a win-switch foraging strategy to choose where to hunt among different locations. They could also return home after inadvertent displacements (Mather, 1991b), so they must have had some simple cognitive map, quite likely guided by visual cues in the environment. This ability was confirmed in the laboratory and extended to cuttlefish (Boal, Dunham, Williams \& Hanlon, 2000).

The use of past information to guide future actions is clearly holding information 'in mind'. Constructing a cognitive map, while it might not be the same kind of map in mammals, birds, insects and cephalopods, is also indicative of mindfulness. Many mobile animals use different solutions to the problem of moving in space; Wiener et al. (2011) talk of different species' use of a 'navigational toolbox'. The use of vision in this ecologically valid situation has recently been much more extensively studied in cuttlefish (Jozet-Alves, Darmaillacq \& Boal, 2014), who can use a combination of cue type, place and time in an episodic-like memory task (Jozet-Alvez et al., 2013). Such 'maps' may be much more widely present in animals. Spiders detour towards prey (Tarsitano, 2006), and foraging bees use exploration as a foundation for flower search (Lihoreau et al., 2012). Carruthers (2007) argues that these actions are evidence that they have a 'mind' (but see Collett, Chittka \& Collett, 2013, for a description of possible combinations of modules).

\section{1.c. What do octopuses think about conspecifics?}

Octopuses are strongly influenced by predation pressure, and their distribution is dominated by the availability of suitable shelter. Aronson (1986) reported a high density of 0 . briareus in a lagoon where predatory fish had been excluded. Hartwick, Breen \& Tulloch (1978) found that E. dofleini were limited by dens in a rocky area. Anderson (1997) found 0 . tetricus 
specifically at reef edges with large numbers of small boulders. Such a pressure to find shelter is easier to discern when octopuses occupy sandy habitat. Mather (1982) found O. joubini to be limited by the presence of empty mollusk shells; Anderson, Hughes, Mather \& Steele (1999) noted that $O$. rubescens's range was extended by the presence of discarded beer bottles; and Katsanevakis \& Verriopoulos (2004) found that $O$. vulgaris used a variety of human trash for shelter. This is important because the crowding of animals in particular areas could be due to either sociality or aggregation.

What is sociality? In its simplest form, it is attraction of animals to conspecifics, in contrast to attraction to special areas in the environment. But sociality should also include some cooperation and recognition of conspecifics or individuals. These were found to be largely absent in octopuses in a review by Boal (2006). Tricarico, Borrelli, Gherardi \& Fiorito (2011) has reported simple habituation to well-known conspecifics in octopuses, and Fiorito \& Scotto (1992) have reported observational learning in $O$. vulgaris from conspecifics, but this research has not been replicated in other laboratories. Boal (2006) noted that there is no indication of cooperative behavior in octopuses and that they are well-known to be cannibals (Ibanez \& Keyl, 2010). Moynihan \& Rodaniche (1982) believed that squid had 'sentinels' at the end of their linear groups to warn others of approaching predators, but Adamo \& Weichelt (1999) found no evidence for this.

It is difficult to evaluate the normal sociality of any animal group. Observations of octopuses in the laboratory are biased because the environment lacks adequate space; octopuses form a dominance hierarchy when thus crowded (see Mather, 1980, for O. joubini; Boyle, 1980, for O. vulgaris; and Cigliano, 1993, for O.bimaculoides). Yet field observations are difficult, uncontrolled and often lacking enough individuals to work past the octopus's huge individual variation (Mather \& Anderson, 1993; see Huffard et al., 2010, for a welcome exception). Octopuses are permanently one sex of two, have internal fertilization and are semelparous, maturing only at the end of the lifespan. In order to continue the species, a male and a female must mate. Negotiating this tricky compromise is difficult for solitary animals, as females can attack courting males (Hanlon \& Forsythe, 2008). One can debate whether temporarily tolerating one another through this process is actually an indication of social sexuality.

The octopus's excellent skin display system seems mostly 'aimed' at the eyes of fish rather than conspecifics. Still, a darkening of the skin with a Mantle-Up posture (Scheel, Godfrey-Smith \& Lawrence, 2016) seems to be agonistic in several species; A. aculeatus males show a stripe display in both male-male and male-female encounters (Huffard et al., 2010). Male octopuses tend to be the active sex; and as they mature, males seek out less active females (see Mather, 1980, for $O$. joubini in the laboratory; personal observations of $O$. vulgaris and $O$. cyanea). They probe into the female's mantle cavity to transfer spermatophores to them, perhaps attracted by chemical cues.

Recently, Scheel et al. (2016) found O. tetricus gathered in a mound of scallop shells. They observed many interactions and suggested that we should no longer consider octopuses to be solitary animals. However, the bulk of evidence, including their own study, still suggests that they are solitary. As in the laboratory, the crowded octopuses in the 'Octopolis' site formed something like a dominance hierarchy. Some exhibited the agonistic Mantle-Up posture, although the skin darkening during this display was only statistically different from its appearance at other times. This was perhaps a general arousal leading to more chromatophore muscle tension and not a stereotyped display. In addition, despite the 
habituation that must have occurred, fully $72 \%$ of all octopus social 'contacts' were simple arm extensions without even touching the other octopus.

Abdopus is clearly the most social of this solitary group. Huffard et al. (2010) recorded 29 male-male contests and 28 instances of mate guarding in A. aculeatus. There were no instances of female-female contact, but there were agonistic interactions between courting males and between males and females. Males used the stripe display during courtship and contests; the larger individual 'won' most contests. Because the ecology of A. aculeatus was not part of the study, we know nothing about whether octopuses were also crowded in that particular habitat. This species is definitely the most social octopus known, but its sociality was only seen in the reproductive context, not a situation in which much thought is likely to be involved. We need many more field observations before we can ascertain the extent of octopus sociality.

It is easier to describe the behaviors of the animals as above than to theorize about the competencies and motivations underlying these behaviors on the assumption of a mind that is processing input and directing multilevel output. Yet with their self-knowledge, sensory and cognitive specialization and social organization, octopuses could also be seen as driven by a combination of curiosity and fear. The following is an attempt to infer their underlying motivation.

\section{What are the motivational bases of octopus behavior?}

\section{2.a. Exploration: What might I do with this object?}

Exploration has not been well-studied (Renner, 1990) and even less so in the octopus, yet it can serve as an important example of planning and forethought. We tend to restrict experimental animals in the laboratory to simplistic situations with a food reward, assuming that we have thereby tapped into all that they can express. Exploration is not simple and there are costs to it, both as energy expended and in risk of predation, but these costs are probably balanced by learning for future situations (Inglis, Langton, Forkman \& Lazarus, 2001).

Extrinsic exploration gains information for a specific context; intrinsic exploration does so in situations that have no obvious biological importance. Octopuses are physically well-equipped for exploration, with their eight sucker-laden arms, yet the motivational underpinning that drives such investigation is difficult to analyze. One way to look at the value of exploration is to use experimental data from formal studies of a highly exploratory New Zealand parrot species, the kea.

Keas are described as "bold, curious and ingeniously destructive" (p. 296) - adjectives that have also been applied to octopuses. Their diet choice is very wide, and they live in a variable and complex environment (Huber \& Gajdon, 2006), as do octopuses. Like other birds and mammals that are thought to have complex cognition and problem solving (Emery \& Clayton, 2004) but unlike octopuses, keas live fairly long lives and have a protracted and protected developmental period. Keas perform a wide variety of play behaviors (Diamond \& Bond, 2004). They tend to switch from social to object play, and playing is not just exhibited by immature animals but throughout the lifespan. O'Hara, Gajdon \& Huber (2012) studied Keas's successes and failures in various cognitive tasks and concluded that they have a very strong drive to manipulate objects, which sometimes takes precedence over the immediate reward provided in the standard experimental paradigm. They also described the keas as 
having technical (and not social) intelligence (Huber \& Gajdon, 2006), which could be a model for octopuses as well (see Figure 5).

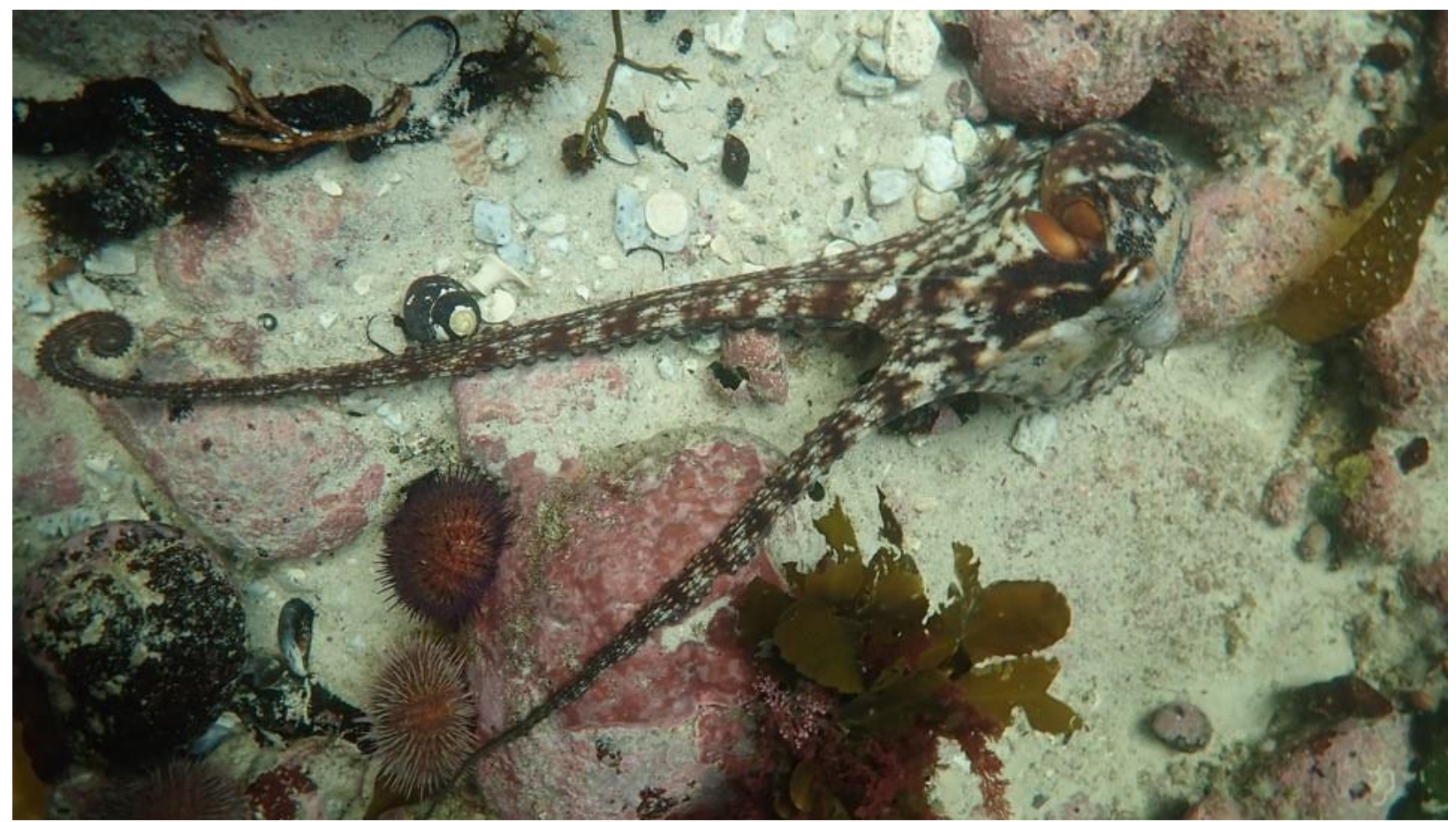

Figure 5: The muscular hydrostat design and the relative independence of individual arms allow the animal to generate extensive chemo-tactile exploration of its environment. (Photo by Craig Foster)

Although exploration in octopuses has only been studied minimally, there are parallels with keas. The primary information about the octopus drive to explore is the extensive lab lore about them. Octopuses in aquariums are often given 'toys'; the AZA (2017) guide for keeping E. dofleini specifies that this species should be given objects to manipulate for enrichment. Such toys mostly contain a food reward, but keepers often comment that their octopuses continue manipulating long after the food has been consumed (Cooke, Tonkins \& Mather, in press). Grasso (personal communication) has also suggested that the octopuses who did the manipulating in his 2008 study seemed to be doing it for the experience and not for the ensuing food reward. An example of 'unmotivated' behavior is that of an E. dofleini at the Seattle Aquarium (named Lucretia McEvil after the cartoon character, the Wicked Witch of the North).

Octopus tanks commonly have a thin basal plastic sheet, attached to the tank corners, with a gravel bed above to give a natural look and to cultivate nitrifying bacteria. One night, Lucretia McEvil dug through the gravel, cut the steel cables attaching the plastic to the tank corners, pulled it up and tore it into pieces, which were found floating at the water surface the next morning (Anderson, personal communication). Octopuses such as Thaumoctopus mimicus commonly imitate the appearance of other animals such as flounders and lionfish (Norman, Finn \& Tregenza, 2001) although no experimental studies have been carried out on the effectiveness of such putative mimicry. Perhaps they sometimes extend this imitation to conspecifics, thus appearing somewhat social despite their normal technical intelligence.

Exploration is seldom systematically studied. However, Kuba, Byrne, Meisel \& Mather (2006a) have studied it, together with habituation, in O. vulgaris. When an item (a miniature 
plastic crab) is moved outside the octopus tank, it quickly habituates both within and across trials. But when food and non-food (Lego blocks) objects are given to the animals, there is a shorter latency to contact food items (extrinsic exploration) than non-food ones (intrinsic exploration); contacts with food are longer but fewer than those with non-food. The number of contacts with food items decreases when animals are satiated (fed two hours earlier) compared to hungry (fed 24 hours earlier), so this exploration does not depend on hunger. In contrast, there are more but shorter contacts with non-food items, and their number is not affected by satiation. Across trials there is a decrease in contact time, but by about the fourth to sixth trial, there is sometimes again an increase.

Mather \& Anderson (1999) set up a 'boring' laboratory situation to elicit play behavior from $E$. dofleini. Isolated octopuses were given a floating pill bottle. Their initial reaction was to grasp it and bring it under the arm web to the mouth. By the third of ten trials, the octopuses ignored it, but by the fifth or sixth trial, two individuals began to aim jets of water at the bottle, which sent it to the other end of the tank, only to have it returned by the current of incoming water - and the octopuses jetted at it again, the marine equivalent of bouncing a ball. Based on Burghardt's (2005) definition, these actions were play. Only some individuals played; the octopuses have such different personalities (Mather \& Anderson, 1993) that no situation elicits the same response from all individuals. This action of emitting a jet of water through the funnel was also used across domains (Chiappe \& McDonald, 2005). The funnel is used by many molluscs as an exit for water circulating through the mantle cavity. The cephalopods have modified it for use in jet propulsion (see Alexander, 2003), but the octopuses also used water jetting in manipulation tasks, such as cleaning out items or sites used as 'homes' and repelling scavenging fish (Mather, 1992) or pesky experimenters (Dews, 1959). Water jets were used at the Seattle Aquarium to short out 24-hour lighting (Anderson, personal communication). Water was being used flexibly as a tool (Mather, 2016b), in different situations.

Kuba, Byrne, Meisel \& Mather (2006b) investigated playful actions of 0 . vulgaris using their arms. Again with the Lego objects, octopuses performed actions on several levels: holding the object with the arms and close to the mouth, moving in the aquarium towing the item, pushing it away from the body and returning it closer, and passing it from arm to arm. Repetition times were used as a measure of 'intensity', and prolonged or repeated actions were considered play. Thus 11 of 21 individuals used play-like actions and one used full play. The sequence across trials went from exploration through habituation to a returned interest and more diverse interactions (see Figure 3.5 in Kuba, Gutnick \& Burghardt, 2014) as had been reported by Mather \& Anderson (1999). Hutt (1966) commented about play in children that it moved from "What is this object?" to "What can I do with this object?" The sequence seems similar for the octopus (p. 76).

Play is much more common in young mammals than adults and is 'functional' as practice for future adaptive behaviours (Burghardt, 2005). Like the keas (Diamond \& Bond, 2004), subadult octopuses in the Kuba et al. (2006b) study did not show more play-like behavior than mature adults. Play might occur when complex animals with a heavy dependence on learning have excess resources and a limited environment and are 'bored' (see discussion by Kuba et al., 2014). Inglis et al. (2001) has pointed out, however, that foraging animals in a complex and varying environment make a tradeoff between immediate use of resources and information acquisition for future use. They explore more when they are satiated and safe, as in the Mather \& Anderson (1993) play situation. This tradeoff between present and potential 
future rewards is also described as 'latent learning' and 'contra-freeloading'. An exploratory animal should proactively test the non-rewarded option in a choice situation. Papini \& Bitterman (1991) noted that the octopuses in their operant test situation could not meet the criterion of eighty percent correct responses, as they often explored the unrewarded choice. This would also be adaptive for the octopus's win-switch foraging strategy (Mather, 1991) and was probably planned by a central controller to focus beyond the immediate reward.

Bryson (2011) has taken such action selection further, suggesting that it provides a role for animal consciousness. She also pointed out the resource allocation tradeoff between automatic responses and learned ones. Plasticity has an advantage in the changing environment of the octopus and the kea, yet it requires attention. More attention is needed if there is more uncertainty; octopuses commonly show such attention allocation (see Baars's, 1997, spotlight analogy). Faced with a difficult situation, the octopuses often made one or several up-and-down head bobs. This allowed the monocular animal to acquire motion parallax information about three-dimensional space (Mather, 2008), a common informationgathering activity across the animal kingdom (Kral, 2003), before choosing an action. This does not require sociality as a precursor to cognitive ability in animals. Rather the 'decisions' that octopuses make while foraging can be described as those of "specializing generalists" (Anderson, Wood \& Mather, 2008). A population often consumes a wide variety of prey species, with some individuals learning special tactics particularly suited for finding one or a few species while others use general tactics suitable for a finding wide variety.

\section{2.b. Fear: Everyone is out to get me}

Since octopuses lack external protection such as armor, spines or toxins, they are vulnerable to attack by a guild of predatory fishes (see Figure 6). Examining the stomach contents of 212 species of reef and inshore Caribbean fish species, Randall (1967) found some remains of cephalopods in the stomachs of most predatory ones. However, only the moray eels are known to consistently hunt octopuses; for example, Mediterranean morays had 5\% octopuses by weight in their stomachs (Matic-Skoko et al., 2014), purplemouth morays in the Caribbean had $12.5 \%$, and spotted snake eels from the same area had 50\% (Randall, 1967). Many of these fish species are diurnally active but the morays are nocturnal, so an octopus would have to be wary at all times of the day and night. Octopuses hid in shelters during times of inactivity but the moray body is elongate and tubular, especially configured for snaking amongst rocks where a resting octopus might be hiding.

What, besides camouflage, might an octopus do to evade these predators? When confined in a divided tank with a black triggerfish, an opportunistic diurnal predator, $O$. vulgaris, shifted activity to become more nocturnal, and the timing of its active periods was negatively correlated with that of the fish (Meisel, Byrne, Mather \& Kuba, 2013). The octopus activity pattern produced near the moray was not a mirror image of this. There was no correlation of the activity of the two animals: instead the octopuses had longer activity bouts in the evening, when the moray might be hunting. This might be a 'risk allocation' strategy, where changing activity in the face of a casual predator was adaptive avoidance. Changing activity towards a specialist predator might only induce a similar shift in its activity; moreover, the moray would attack the octopus in its shelter. Faced with predator species like these two, an octopus might have concluded that it was not safe any time or anywhere. 


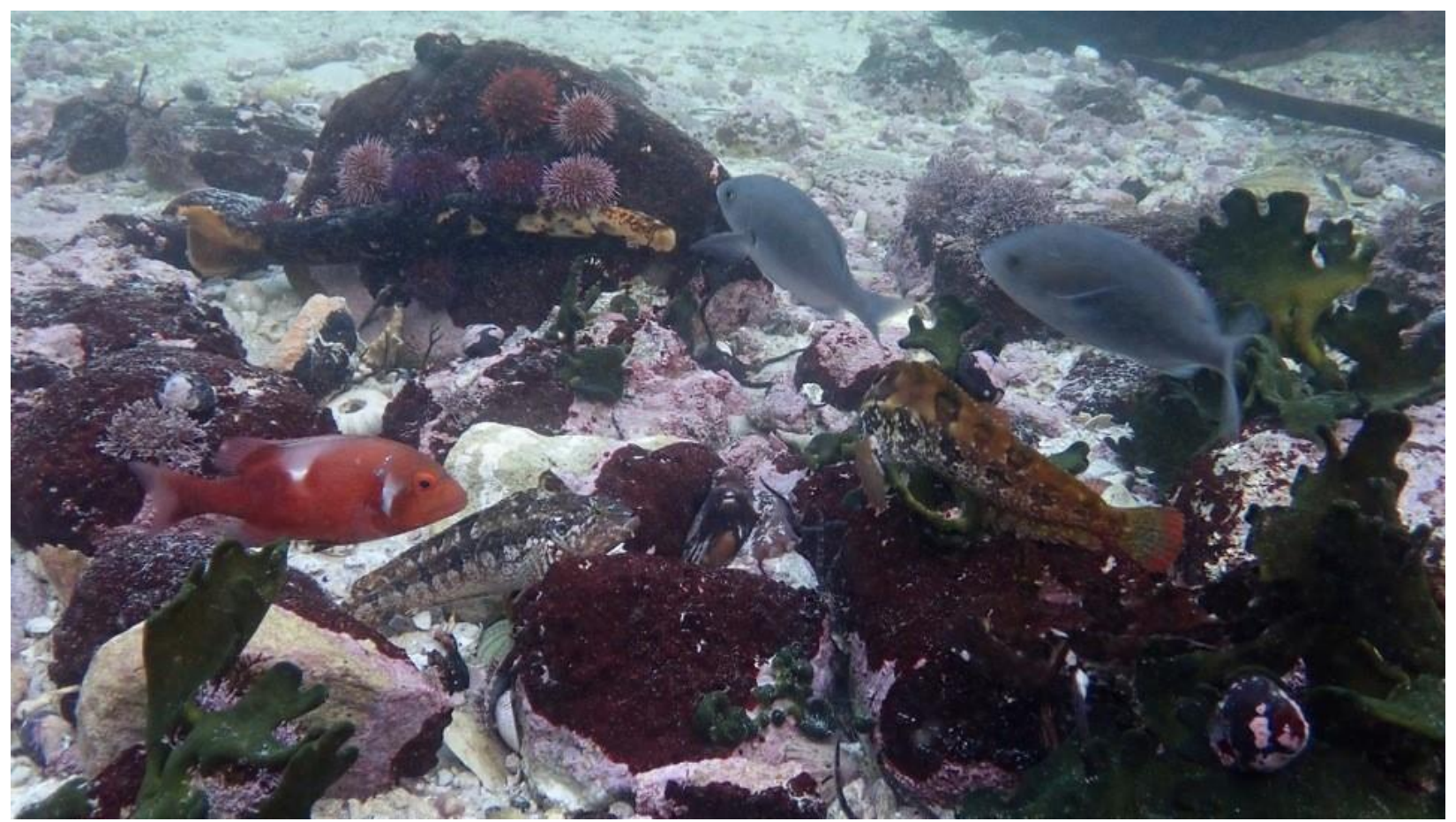

Figure 6: Octopuses (see the individual in the center) are always in danger from scavenging and predatory fish. (Photo by Craig Foster)

Octopuses were not just vulnerable to the guild of predators, particularly fishes, but to crustaceans when they were small and to marine mammals when they grew larger. Octopuses, as well as other coleoid cephalopods, are cannibalistic (Ibanez \& Keyl, 2010). This predatory style is probably an adaptive life history strategy. Cephalopods have poor energy storage; they are semelparous and so have many small offspring and no parental care after hatching. The paralarval octopuses disperse widely in the open ocean, so individuals rarely encounter others related to themselves and there is no opportunity for kin selection. Ibanez \& Keyl (2010) note that the larger octopuses who attack smaller ones also have more smaller individuals available in their 'window' of smaller sized prey. Predatory opportunities could be density-dependent, but the distribution of octopuses may be clumped for the availability of shelter.

Observers rarely see predation events in the field. Moribund octopuses could have been available as food for scavenging conspecifics but there have been a few observations of active cannibalism (see Hanlon \& Forsythe, 2007, and Huffard \& Bartick, 2015, for O. cyanea; Hernandez et al., 2014, for 0 . vulgaris). Death seems to be due to suffocation from compression by the strong arms. Cannibalism happens in several species in the laboratory when there is not enough opportunity to escape but octopuses also hunt conspecifics in the field. Female octopuses actively resist mating attempts by males, so passage of the spermatophore at 'arm's length' from outside the den of a female may be less risky than close contact. Hanlon \& Forsythe (2007) saw a large female attack and eat a smaller male after several copulations, so this activity is by no means safe. For a small male octopus, there must be conflict between the drive to find a female and reproduce and the risk of being killed in the process. The overall chance of reaching adulthood in octopuses ranges from one in 50 or 
so for the large-egged species to one in thousands for the small-egged ones. The intelligent octopus must hence always be on guard, all the time and against everyone.

It is difficult for highly social humans to imagine the totally solitary life of an octopus. There is no support from group members, no sheltered juvenile period, no comforting touch contact and no communication about threat from other group members. An octopus succeeds in reaching maturity and breeding, or more often fails, based only on its own actions and, most of all, on its intelligence.

\section{2.c. Flexibility: If at first you don't succeed, try another way}

While the acquisition and storage of information is clearly vital to animals, how they choose to use it is also very important. Here we must consider both between- and within-individual variations. Across individuals, personality may allow octopuses to adapt to the microenvironment they choose. There are strong personality differences across individuals faced with common situations (Mather \& Anderson, 1993). For example, when O. rubescens were touched on the edge of the mantle with a bristly test-tube brush, reactions varied from jetting away from the brush and ejecting ink to reaching out with a couple of arms and attempting to pull the brush from the experimenter's hand. Dews (1959) found an extreme example of this variation in 0 . vulgaris when he was trying to train three octopuses in operant behavior, pressing a lever at the side of their tank for a food reward. He reported that two of the three octopuses pressed the lever gently and learned the task quickly. The third, Charles, pulled on the lever with great force and eventually broke it. He also pulled down a light suspended above the tank which marked the location of the reward. Between these activities, he aimed jets of water at the experimenter. Since the octopuses were wild-caught, there is no explanation for what might have preceded this suite of behaviors. However, in the field, personality variation of 0 . cyanea has been observed to contribute to their choice of prey (Scheel, Leite, Langford \& Mather, 2016).

Sequences of actions in invertebrates are often assumed to be a fixed set of subroutines, with feedback from the results of one action leading inevitably to the next (see Japyassu \& Laland, 2017, for a discussion). Such sequences are rarely seen in cephalopods, but one such set of actions was investigated during sand burying by the cuttlefish Sepia (Mather, 1986). The sequence was adjusted to subtle changes in the environment such as sand depth and texture. The freedom of such actions from stimulus-response pairing in domain-specific responses indicates control by a mind (Chiappe \& McDonald, 2005); the use of water as a tool in different situations is an instance of such flexibility. Cognitive modules might have evolved to handle specific inputs and generate specialized solutions for them (Vitti, 2013); it is often suggested that human language is such a module. Domain generality is the opposite of modularity; it allows animals to apply old solutions to new problems or to apply several solutions to a continuing problem. Chiappe \& MacDonald (2010) and Japyassu \& Laland (2017) argue that animals are impelled toward this domain generality by living in uncertain and often novel environments, and Shumway (2008) suggests that such environments result in larger brains (see Figure 7). 


\section{EXAMPLES \\ SITUATION \\ Flexibility \\ Activity change in response to generalist predators \\ Skin background matching (pattern, texture, color) \\ Arm use for walking by movement direction \\ Home construction by modification \\ Causal Reasoning \\ Avoidance of stinging sea anemone \\ Passing Cloud skin display \\ Location of hole drilling on clam shells \\ Prospection \\ Head bob to get motion parallex information \\ Coconut carrying to a location with no shelter \\ Return to home after displacement \\ Imagination \\ Arm/tentacle tip wiggle \\ "Pain" behavior \\ Push-pull item manipulation \\ Play by water jet or arms \\ Facultative predation avoidance \\ Use of immediate visual cues \\ Flexible choice by goal direction \\ Learned kinesthetic feedback use \\ Feedback from negative sting \\ Invoking startle action in prey \\ Feedback from previous attempts \\ Response to ambiguous situation \\ Plan for need for future shelter \\ Allocentric view, cognitive map \\ Plan for prey luring \\ Mitigating body damage \\ Different action, same result \\ Boredom relief, domain general}

Figure 7: Examples of actions by octopuses that require the guidance of a mind, including flexibility of actions, causal reasoning, prospection for future actions and imagination of a possible situation (see Emery \& Clayton, 2004).

Octopus adaptability has been used for problem solving across domains. For example, octopuses removed a lid of a glass jar to obtain a crab confined inside, but Fiorito, von Planta and Scotto (1990) found that they did not learn (i.e., did not have a shorter latency to perform the task). Anderson \& Mather (2010) added an extra cue, chemical traces on the outside of the jar, which did produce a decrease in latency. Because the jar was commonly taken under the arm web and out of sight, the octopus did not remember the situation without continuing cueing, but could use the two cues sequentially. There was no stereotyped behavior in this novel situation; one individual tested by the author simply wrapped one arm around the edge of the lid and contracted it to unscrew the lid; the other used the bases of several arms and moved them laterally. When Mather \& Anderson (1999) observed octopuses playing, they were moving a pill bottle with jets of water, but when Kuba et al. (2006b) saw octopuses engaging in play-like behavior with Lego blocks, they were moving them by extending their 
arms and passing an item from arm to arm. As far as choice of action is concerned, octopuses seem to use the principle: 'whatever works'.

Using whatever action is effective can result in sequential problem solving. Capturing a clam in its shell does not result in an immediate food reward because of what Anderson \& Mather (2007) called the 'packaging problem'. Initially, octopuses tried to use the energetically demanding and short-duration strategy of pulling the valves apart, but if they did not succeed (Wodinsky, 1969), they used other strategies (McQuaid, 1994). The initial pull may also be a short evaluative one, with that initial resistance cuing the octopus to switch strategies. Octopuses can then drill a small hole in the shell with their salivary papilla (Nixon \& Macconachie, 1988) and send a posterior salivary gland toxin through the hole, weakening the clam's muscles. Alternatively, they can chip a small piece off the margin of the valve with their cartilaginous beak, which also provides an area for inserting the toxin (Anderson \& Mather, 2007).

These three techniques require different orientations of the clam to the octopus's mouth, carried out under the arm web and thus not available to vision. For pulling, the clam is positioned with the hinge towards the octopus's mouth; for drilling, the flat area of one valve of the clam is placed near the mouth and for chipping, the anterior or posterior margin of the clam is angled toward the beak/mouth area. Interestingly, the drilled hole is either positioned over the clam adductor muscles or over its heart, and drilling locations must have been learned, but quickly (Merlino, 2013). The octopuses consumed a variety of prey species, and the effective hole position is learned for each. Blustein \& Anderson (2016) describe the specialized posterior-lateral location necessary for drilling holes over the retractor muscle of cowries. The effort involved in drilling influences prey choice, too. With a choice between fragile-shelled mussels that need no drilling or chipping and two stronger clams that do, $E$. dofleini more often chooses the mussels. However, if the bivalves are already opened first, the octopuses nearly ignore the mussels (Anderson \& Mather, 2007). The energy tradeoff between actions and food return is evaluated not only in the choice of what penetration strategy to use but also the choice of prey species, maximizing energy gain over expenditure.

Octopuses also use sequential problem solving in a more perilous situation: predator threat. The primary protection from most predators is to hide: 0 . insularis (thought at the time to be vulgaris) only came out to hunt for $13 \%$ of the daytime (Mather, 1988). The octopus's excellent skin pattern camouflage (Messenger, 2001), sometimes accompanied by Concealing postures (Huffard, 2006), was a primary protection when they hunted. If octopuses were approached more closely by a predator, they changed to a wide spread of arms and web and dark around the eyes, producing a startle pattern (Mather et al., 2014, Figure 6.4). If this action failed to repel the predator, the octopuses could make a jet-propelled departure, often changing appearance sequentially, which breaks the continuity of the predator's 'search image' (Bond, 2007). Jetting could be accompanied by the release of ink, which both obscured the predator's vision and blocked its chemoreception (Wood et al., 2010). In the large Octopus cyanea, concealment may be more a matter of variation than background matching (Hanlon, Forsythe \& Joneschild, 1999). Foraging animals of this species made many changes in their appearance, three per minute; these patterns were only camouflaging about half the time. With approximately 11 patterns, none could be easily anticipated for prey recognition. This proactive strategy of variation might mean that a 
predator searching visually would not be able to match any one appearance with its stored search image (Bond, 2007). During a prolonged chase, the octopuses intersperse these changes with ink and a jet escape, further confusing the potential predator. Changing was protection.

\section{Conclusion}

Although we hold up learning as the hallmark of intelligence and mental competence, many types of learning are very simple and widespread throughout the animal kingdom. Deaner (2006) has pointed out for primates and Zarrella et al. (2016) for octopuses that the number of situations in which animals can learn may be a more appropriate measure of their intelligence. Cephalopods acquire many new input-response linkages in demanding experimental situations such as those requiring episodic memory (Jozet-Alves et al., 2014), as well as ecologically valid ones such as navigating through the environment (Mather, 1991a; Jozet-Alves et al., 2014). Octopuses are also excellent domain general learners, with the flexibility to use the same actions in different situations (Vitti, 2013) or different actions in the same situation (Mather, 2016b). Octopuses can change their situation-action pairings too, trying a different response when an old one has failed, which is particularly vital when a predator threatens (Hanlon et al., 1999; Mather et al., 2014).

The ability to flexibly acquire information through learning, and to use it in a domain general manner in constructs such as a cognitive map, provides potential evidence for a mind. The capacity to acquire proactive information is even more compelling. Focusing on learning, theorists had seen exploration as 'latent learning' or 'contra-freeloading'. Inglis et al. (2001) recognized exploration as an adaptive tradeoff between the immediate use of information and the acquisition of information for future use; octopuses are specialists in this. They use the head bob to generate motion parallax to acquire three-dimensional information for their monocular visual system. They generate a Passing Cloud skin display to startle a motionless prey after a capture attempt has failed (Mather \& Mather, 2004). They can acquire information from tactile exploration and then generalize it to play and the manipulation of objects. I suggest that such capacities need to be directed by a mind. Although the sensory Umwelt and the decentralized control systems of the octopus do not generate the same kind of mind as in vertebrates, the octopus nevertheless has one.

Acknowledgements: The author wishes to thank Leanne Wehlage-Ellis and Graham McKenzie for organization and word processing. The photos are by Craig Foster, award-winning filmmaker and founder of the Sea-Change Project. The Passing Cloud video is by Jean S. Alupay-Andreoli, PhD, Greater Farallones National Marine Sanctuary. 
Call for Commentary: Animal Sentience publishes Open Peer Commentary on all accepted target articles. Target articles are peer-reviewed. Commentaries are editorially reviewed. There are submitted commentaries as well as invited commentaries. Commentaries appear as soon as they have been reviewed, revised and accepted. Target article authors may respond to their commentaries individually or in a joint response to multiple commentaries.

\section{INSTRUCTIONS FOR COMMENTATORS}

\section{References}

Adamo, S. A. \& Weichelt, K. J. (1999). Field observations of schooling in the oval squid, Sepioteuthis lessoniana (Lesson, 1830). Journal of Molluscan Studies, 65, 377-380.

Alupay, J. A., Hadjisolomou, S. P. \& Crook, R. J. (2014). Arm injury produces long-term behavioral and neural hypersensitivity in octopus. Neuroscience Letters, 558, 137-142.

Anderson, R. C., Hughes, P. C., Mather, J. A. \& Steele, C. W. (1999). Determination of the diet of Octopus rubescens Berry, 1953 (Cephalopoda: Octopodidae) through examination of its beer bottle dens in Puget Sound. Malacologia, 41, 455-460.

Anderson. R. C. \& Mather, J. A. (2007). The packaging problem: Bivalve mollusk prey selection and prey entry techniques of Enteroctopus dofleini. Journal of Comparative Psychology, 121, 300-305.

Anderson, R. C. \& Mather, J. A. (2010). It's all in the cues: Octopuses (Enteroctopus dofleini) learn to open jars. Ferrantia, 59, 22031.

Anderson, R. C., Mather, J. A., Monette, M. Q. \& Zimsen, S. R. M. (2010). Octopuses (Enteroctopus dofleini) recognize individual humans. Journal of Applied Animal Welfare Science, 13, 261-272.

Anderson, R. C., Wood J. B. \& Mather, J. A. (2008). Octopus vulgaris in the Caribbean is a specializing generalist. Marine Ecology Progress Series, 371, 199-202.

Anderson, T. J. (1997). Habitat selection and shelter use by Octopus tetricus. Marine Ecology Progress Series, 150, 137-148.

Aronson, R. B. (1991). Ecology, paleobiology and evolutionary constraints in the octopus. Bulletin of Marine Science, 49, 245-255.

AZA Aquatic Invertebrate Taxonomic Advisory Group (AITAG). (2014). Giant Pacific Octopus (Enteroctopus dofleini) care manual. Silver Springs, MD: American Zoological Association.

Baars, B. J. (1997). In the theatre of consciousness: Global workplace theory: A rigorous scientific theory of consciousness. Journal of Consciousness Studies, 4, 292-309.

Blustein, D. H. \& Anderson, R. C. (2016). Localization of octopus drill holes on cowries. American Malacological Bulletin, 34, 1-4.

Boal, J. G. (2006). Social recognition: A top-down view of cephalopod behavior. Vie et Milieu, 56, 6979.

Boal, J. G., Dunham, A. W., Williams, K. T. \& Hanlon, R. T. (2000). Experimental evidence for spatial learning in octopuses (Octopus bimaculoides). Journal of Comparative Psychology, 114, 246-252.

Bond, A. B. (2007). The evolution of color polymorphisms: Crypticity, searching images, and apostatic selection. Annual Review of Ecology and Systematics, 38, 489-514.

Boyle, P. R. (1980). Home occupancy by male Octopus vulgaris in a large seawater tank. Animal Behaviour, 28, 1123-1126.

Brown, C., Garwood, M. P. \& Williamson, J. E. (2012). It pays to cheat: Tactical deception in a cephalopod social system. Biological Letters, rsbl20120435.

Bryson, J. J. (2011). A role for consciousness in action selection. Paper presented at Proceedings of the AISB 2011 Symposium: Machine Consciousness, 15-20. University of York, UK. 
Bublitz, A., Weinhold, S. R., Strobel, S., Dehnhardt, G. \& Hanke, F. (2017). Reconsideration of serial visual reversal learning in octopus (Octopus vulgaris) from a methodological perspective. Frontiers in Psychology, 8, 54.

Buresch, K. C., Ulmer, K. M. Akkaynak, D., Allen, J., Mäthger, L. M., Nakamura, M. \& Hanlon, R. T. (2015). Cuttlefish adjust body pattern intensity with respect to substrate intensity to aid camouflage, but do not camouflage in extremely low light. Journal of Experimental Marine Biology and Ecology, 462, 121-126.

Burghardt, G. M. (2005). The genesis of animal play. Cambridge, MA: MIT Press.

Byrne, R. A., Kuba, M. J., Meisel, D. V. Griebel, U. \& Mather, J. A. (2006a). Does Octopus vulgaris have preferred arms? Journal of Comparative Psychology, 120, 198-204.

Byrne, R. A., Kuba, M. J., Meisel, D. V., Griebel, U. \& Mather, J. A. (2006b). Octopus arm choice is strongly influenced by eye use. Behavioral Brain Research, 172, 195-201.

Carls-Diamante, S. (2017). The octopus and the unity of consciousness. Biological Philosophy, 32, 1269-1287.

Carruthers, P. (2007). Invertebrate minds: A challenge for ethical theory. The Journal of Ethics, 11, 275-297.

Cartron, L., Darmaillacq, A-S., Jozet-Alves, C., Shashar, N. \& Dickel, L. (2012). Cuttlefish rely on both polarized light and landmarks for navigation. Animal Cognition, 15, 591-596.

Cartron, L., Josef, N., Lerner, A., McCusker, S. D., Darmaillacq, A-S., Dickel, L. \& Shashar, N. (2013). Polarization vision can improve object detection in turbid waters by cuttlefish. Journal of Experimental Marine Biology and Ecology, 447, 80-85.

ten Cate, J. (1928). Contribution à l'innervation des ventouses chez Octopus vulgaris. Archive Neerlandaises de Physiologie de l'Homme et des Animaux, 13, 407-422.

Chiao, C-C., Chubb, C. \& Hanlon, R. T. (2015). A review of visual perception mechanisms that regulate rapid adaptive camouflage in cuttlefish. Journal of Comparative Physiology A, 201, 933-945.

Chiao, C-C., Wickiser, J. K., Allen, J., Genter, B. \& Hanlon, R. T. (2011). Hyperspectral imaging of cuttlefish camouflage indicates good color match in the eyes of fish predators. Proceedings of the National Academy of Sciences, 108, 9148-9153.

Chiappe, D. \& MacDonald, K. (2005). The evolution of domain-general mechanisms in intelligence and learning. The Journal of General Psychology, 132, 5-20.

Cigliano, J. A. (1993). Dominance and den use in Octopus bimaculoides. Animal Behaviour, 46, 677684.

Clayton, N. (1993). Lateralization and unilateral transfer of spatial memory in marsh tits. Journal of Comparative Physiology A, 171, 799-805.

Collett, M., Chittka, L. \& Collett, T. S. (2013). Spatial memory in insect navigation. Current Biology, 23, R789-R800.

Cooke, G. M., Tonkins, B. M. \& Mather, J. A. (in press). Environment for captive cephalopods. In C. Carere \& J. A. Mather (Eds.), Welfare of invertebrates. New York, NY: Springer.

Deaner, R. O., van Schaik, C. P. \& Johnson, C. P. (2006). Do some taxa have better domain-general cognition than others? A meta-analysis of nonhuman primate studies. Evolutionary Psychology, 4, 149-196.

Dews, P. M. (1959). Some observations of an operant in an octopus. Journal of Experimental Analysis of Behavior, 8, 57-63.

Diamond, J. \& Bond, A. B. (2003). A comparative analysis of social play in birds. Behaviour, 140, 1091-1115.

Dilly, N., Nixon, M. \& Packard, A. (1964). Forces exerted by Octopus vulgaris. Pubblicazione della Stazione Zoologica di Napoli, 34, 86-97.

Dukas, R. (1998). Evolutionary ecology of learning. In R. Dukas (Ed.), Cognitive ecology (pp. 129174). Chicago, IL: University of Chicago Press. 
Emery, N. J. \& Clayton, N. (2004). The mentality of crows: Convergent evolution of intelligence in corvids and apes. Science, 306, 1903-1907.

Finn, J. K., Tregenza, T. \& Norman, M. D. (2009). Defensive tool use in a coconut-carrying octopus. Current Biology, 19, 1029-1030.

Fiorito, G. \& Scotto, P. (1992). Observational learning in Octopus vulgaris. Science, 256, 545-547.

Fiorito, G., von Planta, C. \& Scotto, P. (1990). Problem solving ability of Octopus vulgaris Lamarck (Mollusca, Cephalopoda). Behavioral and Neural Biology, 53, 217-230.

Gallup, G. G. (1995). Self-recognition: Research strategies and experimental design. In: S. T. Parker, R. W. Mitchell \& M. Boccia (Eds.), Self-awareness in animals and humans (pp. 35-50). Cambridge, UK: Cambridge University Press.

Gibson, J. J. (1966). The senses considered as perceptual systems. Boston, MA: Houghton Mifflin.

Gleadall, I. G. \& Shashar, N. (2004). The octopus' garden: The visual world of cephalopods. In F. R. Prete, (Ed.), Complex worlds from simpler visual systems (pp. 269-308). Cambridge, MA: MIT Press.

Godfrey Smith, P. (2016). Other minds: The octopus, the sea, and the deep origin of consciousness. New York, NY: Farrar, Strauss \& Giroux.

Gonzalez-Bellido, P. T., Scaros, A. T., Hanlon, R. T. \& Wardill, T. J. (2018). Neural control of dynamic 3-dimensional skin papillae for cuttlefish camouflage. iScience, 1, 24-34.

Grasso, F. W. (2008). Octopus sucker-arm coordination in grasping and manipulation. American Malacological Bulletin, 24, 13-23.

Grasso, F. W. (2014). The octopus with two brains: How are distributed and central representations integrated in the octopus? In: A-S. Darmaillacq, L. Dickel \& J. A. Mather (Eds.), Cephalopod cognition (pp. 94-112). Cambridge, UK: Cambridge University Press.

Gutnick, T., Byrne, R., Hochner, B. \& Kuba, M. (2011). Octopus vulgaris uses visual information to determine the location of its arms. Current Biology, 21, 460-462.

Hall, K. \& Hanlon, R. (2002). Principal features of the mating system of a large spawning aggregation of the giant Australian cuttlefish Sepia apama (Mollusca: Cephalopods). Marine Biology, 140, 533-545.

Hanlon, R. T. \& Forsythe, J. W. (2008). Sexual cannibalism by Octopus cyanea on a Pacific coral reef. Marine and Freshwater Behaviour and Physiology, 41, 19-28.

Hanlon, R. T. \& Messenger, J. B. (2018). Cephalopod behavior, 2nd ed. Cambridge, UK: Cambridge University Press.

Hanlon, R. T., Forsythe, J. W. \& Joneschild, D. E. (1999). Crypsis, conspicuousness, mimicry and polyphenism as antipredator defenses of foraging octopuses in Indo-Pacific coral reefs, with a method of quantifying crypsis from videotapes. Biological Journal of the Linnaean Society, 66, 122.

Hartwick, E. B., Breen, P. A. \& Tulloch, L. (1978). A removal experiment with Octopus dofleini. Journal of the Fisheries Research Board of Canada, 35, 1492-1495.

Hernandez-Ucera, J., Garci, M. E., Roura, A., Gonzales, A. F., Cabanellas-Reboredo, M., Morales-Nin, B. \& Guerra, A. (2004). Cannibalistic behavior of octopus (Octopus vulgaris) in the wild. Journal of Comparative Psychology, 128, 427-430.

Hochner, B. (2012). An embodied view of octopus neurobiology. Current Biology, 22, R887-R892.

Hochner, B. \& Shomrat, T. (2014). The neurophysiological basis of learning and memory in an advanced invertebrate: The octopus. In: A-S. Darmaillacq, L. Dickel \& J. A. Mather (Eds.), Cephalopod cognition (pp. 72-93). Cambridge, UK: Cambridge University Press.

Huber, L. \& Gajdon, G. K. (2006). Technical intelligence in animals: The kea model. Animal Cognition, 9, 295-305.

Huffard, C. L. (2006). Locomotion by Abdopus aculeatus (Cephalopoda: Octopodidae): Walking the line between primary and secondary defenses. Journal of Experimental Biology, 209, 3697-3707. 
Huffard, C. L. \& Bartick, M. (2012). Wild Wunderpus photogenicus and Octopus cyanea employ asphyxiating 'constricting' in interaction with other octopuses. Molluscan Research, 35, 12-16.

Huffard, C. L., Caldwell, R. L. \& Boneka, F. (2008). Mating behavior of Abdopus aculeatus (D’Orbigny, 1834) (Cephalopoda: Octopodidae) in the wild. Marine Biology, 154, 353-362.

Huffard, C. L., Caldwell, R. L. \& Boneka, F. (2010). Male-male and male-female aggression may influence mating association in wild octopuses (Abdopus aculeatus). Journal of Comparative Psychology, 124, 38-46.

Hutt, C. (1966). Exploration and play in children. Symposium of the Zoological Society of London, 18, 61-81.

Ibanez, C, M. \& Keyl, F. (2010). Cannibalism in cephalopods. Review of Fisheries and Fish Biology, 20, 123-136.

Inglis, I. R., Langton, S., Forkman, B. \& Lazarus, J. (2001). An information primacy model of exploratory and foraging behaviour. Animal Behaviour, 62, 543-557.

Japyassu, H. F. \& Laland, K. N. (2017). Extended spider cognition. Animal Cognition, 20, 375-395.

Jordan, L. M., Brownstone, R. M. \& Noga, R. (1992). Control of functional systems in the brainstem and spinal cord. Current Opinions in Neurobiology, 2, 794-801.

Josef, N., Amodio, P., Fiorito, G. \& Shashar, N. (2012). Camouflaging in a complex environmentoctopuses use specific features of their surroundings for background matching. PLoS ONE, 7 (5), e37579.

Jozet-Alves, C., Bertin, M. \& Clayton, N. S. (2013). Evidence of episodic-like memory in cuttlefish. Current Biology, 23, R1033-R1035.

Jozet-Alves, C., Darmaillacq, A-S. \& Boal, J. G. (2014). Navigation in cephalopods. In A-S. Darmaillacq, L. Dickel \& J. A. Mather (Eds.), Cephalopod cognition (pp. 150-176). Cambridge, UK: Cambridge University Press.

Jozet-Alves, C., Moderan, J. \& Dickel, L. (2008). Sex differences in spatial cognition in an invertebrate: The cuttlefish. Proceedings of the Royal Society B: Biological Sciences, 275, 2049-2054.

Ju, C., Wu, L., Zhao, W. \& Lv, J. (2012). Echinoderms have bilateral tendencies. PLoS ONE, 7, e28978.

Katsanevakis, S. \& Verriopoulos, G. (2004). Den ecology of Octopus vulgaris Cuvier, 1797, on soft sediment: Availability and types of shelters. Scientia Marina, 68, 147-157.

Kier, W. M. \& Smith, K. K. (1985). Tongues, tentacles and trunks: The biomechanics of movement in muscular-hydrostats. Zoological Journal of the Linnean Society, 83, 307-324.

Kier, W. M. \& Smith, A. M. (2002). The structure and adhesive mechanism of octopus suckers. Integrative and Comparative Biology, 42, 1146-1153.

Kral, K. (2003). Behavioural-analytic studies of the role of head movements in depth perception in insects, birds and mammals. Behavioural Processes, 64, 1-12.

Kuba, M. J., Byrne, R., Meisel, D. V. \& Mather, J. A. (2006a). Exploration and habituation in intact free moving Octopus vulgaris. International Journal of Comparative Psychology, 19, 426-438.

Kuba, M. J., Byrne, R., Meisel, D. V. \& Mather, J. A. (2006b). When do octopuses play? Effects of repeated testing, object type, age, and food deprivation on object play in Octopus vulgaris. Journal of Comparative Psychology, 120, 184-190.

Kuba, M. J., Gutnick, T. \& Burghardt, G. (2014). Learning from play in octopus. In: A-S. Darmaillacq, L. Dickel \& J. A. Mather (Eds.), Cephalopod cognition (pp. 57-71). Cambridge, UK: Cambridge University Press.

Langridge, K. V., Broom, M. \& Osorio, D. (2007). Selective signaling by cuttlefish to predators. Current Biology, 17, 1044-1045.

Levy, G., Flash, T. \& Hochner, B. (2015). Arm coordination in crawling involves unique motor coordination strategies. Current Biology, 25, 119501200.

Lihoreau, M., Raine, N. E., Reynolds, A. M., Stelzer, R. J., Lim, K. S., Smith, A. D., Osborne, J. L. \& Chittka, L. (2012). Radar tracking and motion-sensitive cameras on flowers reveal the development of pollinator multi-destination routes over large spatial scales. PLoS ONE. 
Liu, T. H. \& Chiao, C-C. (2016). Mosaic organization of body pattern control in the optic lobe of squids. Journal of Neuroscience, 37, 768-780.

Mather, J. A. (1980). Social organization and use of space by Octopus joubini in a semi-natural situation. Bulletin of Marine Science, 30, 848-857.

Mather, J. A. (1982). Factors affecting the spatial distribution of natural populations of Octopus joubini Robson. Animal Behaviour, 30, 1166-1170.

Mather, J. A. (1988). Daytime activity of juvenile Octopus vulgaris in Bermuda. Malacologia, 29, 6976.

Mather, J. A. (1991a). Foraging, feeding and prey remains in middens of juvenile Octopus vulgaris (Mollusca: Cephalopoda). Journal of Zoology, London, 224, 27-39.

Mather, J. A. (1991b). Navigation by spatial memory and use of visual landmarks in octopuses. Journal of Comparative Physiology A, 168, 491-497.

Mather, J. A. (1992). Interaction of juvenile Octopus vulgaris with scavenging and territorial fishes. Marine and Freshwater Behaviour and Physiology, 19, 175-182.

Mather, J. A. (1998). How do octopuses use their arms? Journal of Comparative Psychology, 112, 306316.

Mather, J. A. (2008). Cephalopod consciousness: Behavioural evidence. Consciousness and Cognition, 17, 37-48.

Mather, J. A. (2010). Vigilance and antipredator responses of Caribbean reef squid. Marine and Freshwater Behaviour and Physiology, 43, 357-370.

Mather, J. A. (2016a). Mating games squid play: Reproductive behavior and sexual skin displays in Caribbean reef squid Sepioteuthis sepioidea. Marine and Freshwater Behaviour and Physiology, 49, 359-373.

Mather, J. A. (2016b). Cephalopod tool use. Encyclopedia of Evolutionary Psychological Science, 1-5.

Mather, J. A. \& Alupay, J. (2016). An ethogram for octopuses of the family Octopodidae. Journal of Comparative Psychology, 130, 109-127.

Mather, J. A. \& Anderson, R. A. (1993). "Personalities" of octopuses (Octopus rubescens). Journal of Comparative Psychology, 107, 336-340.

Mather, J. A. \& Anderson, R. A. (1999). Exploration, play and habituation in Octopus dofleini. Journal of Comparative Psychology, 113, 333-338.

Mather, J. A. \& Dickel, L. (2017). Cephalopod complex cognition. Current Opinion in Behavioral Sciences, 16, 131-137.

Mather, J. A. \& Kuba, M. C. (2018). Octopuses-mind in the waters. In: N. Bueno Guerra \& F. Amici (Eds.), Field and laboratory methods in animal cognition. Cambridge, UK: Cambridge University Press.

Mather, J. A. \& Mather, D. L. (2004). Apparent movement in a visual display: The Passing Cloud in Octopus cyanea. Journal of Zoology, London, 263, 89-94.

Mather, J. A., Carere, C., Fiorito, G. \& Anderson, R. C. (2018). Octopuses and mirrors: A tale of two species. Paper presented at the annual meeting of the Animal Behavior Society, Milwaukee, WI.

Mather, J. A., Leite, T. S., Anderson, R. A. \& Wood, J. B. (2014). Foraging under the risk of predation and the development of intelligence in octopuses. In A-S. Darmaillacq, L. Dickel \& J. A. Mather (Eds.), Cephalopod Cognition (pp. 125-149). Cambridge, UK: Cambridge University Press.

Mäthger, L., Shashar, N. \& Hanlon, R. T. (2009). Do cephalopods communicate using polarized light reflections from their skin? Journal of Experimental Biology, 212, 2133-2140.

Matik-Skoko, S., Tutman, P., Varezic, D. B., Skaramuca, D., Dikik, D., Liscic, D. \& Skaramuca, B. (2014). Food preferences of the Mediterranean moray eel, Muraena helena (Pisces: Muraenidae), in the southern Adriatic. Marine Biology Research, 10, 807-815.

McCrea, D. A. (2004). Spinal circuitry of sensorimotor control of locomotion. Journal of Physiology, $533,41-50$. 
McNeill Alexander, R. (2003). Principles of animal locomotion. Princeton, NJ: Princeton University Press.

McQuaid, C. D. (1994). Feeding behavior and selection of bivalve prey by Octopus vulgaris Cuvier. Journal of Experimental Marine Biology and Ecology 177, 187-202.

Meisel, D. V., Byrne, R., Mather, J. A. \& Kuba, M. (2013). The effect of predatory presence on the temporal organization of activity in Octopus vulgaris. Journal of Experimental Marine Biology and Ecology, 447, 75-79.

Merlino, B. (2013). Predation behavior of Octopus joubini Cuvier. Unpublished MSc. thesis, New College of Florida.

Messenger, J. B. (2001). Cephalopod chromatophores: Neurobiology and natural history. Biological Reviews, 76, 473-528.

Moynihan, M. H. \& Rodaniche, A. F. (1982). The behavior and natural history of the Caribbean reef squid Sepioteuthis sepioidea with a consideration of social, signal and defensive patterns for difficult and dangerous environments. Advances in Ethology, 125, 1-150.

Nagel, T. (1974). What is it like to be a bat? Philosophical Reviews, 83, 435-450.

Nesher, N., Levy, G., Grasso, F. W. \& Hochner, B. (2014). Self-recognition mechanism between skin and suckers prevents octopus arms from interfering with each other. Current Biology, 24, 12711275.

Nixon, M. \& Macconachie, E. (1988). Drilling by Octopus vulgaris (Mollusca, Octopodidae) in the Mediterranean. Journal of Zoology, 216, 687-716.

Norman, M. D., Finn, J. \& Tregenza, T. (2001). Dynamic mimicry in an Indo-Malaysian octopus. Proceedings of the Royal Society of London B, 268, 1755-1758.

O'Hara, M., Gajdon, G. \& Huber, L. (2012). Kea logic: How these birds solve difficult problems and outsmart researchers. In S. Watanbe (Ed.), Logic and Sensibility, 23-37. Tokyo, Japan: Keio University Press.

Packard, A. (1972). Cephalopods and fish: The limits of convergence. Biological Reviews, 47, 241307.

Papini, M. R. \& Bitterman, M. E. (1991). Appetitive conditioning in Octopus cyanea. Journal of Comparative Psychology, 105, 107-113.

Pepperberg, I. M., Garcia, S. E., Jackson, E. C. \& Marconi, S. (1995). Mirror use by African grey parrots (Psittaceus erithacus). Journal of Comparative Psychology, 109, 182-195.

Polese, G., Bertapelli, C. \& DiCosmo, A. (2015). Olfactory organ of Octopus vulgaris: Morphology, plasticity, turnover and sensory characterization. Biology Open, 5, 611-619.

Randall, J. E. (1967). Food habits of reef fishes of the West Indies. Studies in Tropical Oceanography, $5,665-847$.

Renner, M. J. (1990). Neglected aspects of exploratory and investigative behavior. Psychobiology, 18, 16-22.

Richter, N. J., Hochner, B. \& Kuba, M. (2015). Octopus arm movements under constrained conditions: Adaptation, modification and plasticity of motor primitives. Journal of Experimental Biology, 218, 1035-1041.

Scheel, D., Godfrey-Smith, P. \& Lawrence, M. (2016). Octopus use signals during frequent conspecific interactions. Current Biology, 26, 377-382.

Scheel, D., Langford, K., Leite, T. S. \& Mather, J. A. (2017). Habitat ecology, diet and foraging of Octopus cyanea in Moorea, French Polynesia. Journal of Natural History, 51, 2615-2633.

Schnell, A. K., Hanlon, R. T., Benkada, A. \& Jozet-Alves, C. (2016). Lateralization of eye use in cuttlefish: Opposite directions for predator and antipredator behavior. Frontiers in Physiology, 7, 620.

Shigeno, S., Andrews, P. L., Ponte, G. \& Fiorito, G. (2018). Cephalopod brains: An overview of current knowledge to facilitate comparison with vertebrates. Frontiers in Physiology, 9. 
Shumway, C. A. (2008). Habitat complexity, brain, and behavior. Brain, Behavior and Evolution, 72, 123-134.

Sutherland, N. S. (1957). Visual discrimination of orientation and shape by the octopus. Nature, 179, 11-13.

Tarsitano, M. S. (2006). Route selection by a jumping spider (Portia labiata) during the locomotory phase of a detour. Animal Behaviour, 72, 1437-1442.

Tricarico, E., Borelli, L., Gherardi, F. \& Fiorito, G. (2011). I know my neighbour: Individual recognition in Octopus vulgaris. PLoS ONE, 6, e18710.

Vitti, J. J. (2013). Cephalopod cognition in an evolutionary context: Implications for ethology. Biosemiotics, 6, 393-401.

Von Uexcull, J., von Uexcull, M. \& O’Neill, J. D. (1934:2010). A foray into the worlds of animals and humans: With a theory of meaning. Minneapolis, MN: University of Minnesota Press.

Walker, J. J., Longo, N. \& Bitterman, M. E. (1970). The octopus in the laboratory: Handling, maintenance, training. Behavior Research Methods and Instrumentation, 2, 15-18.

Wells, M. J. (1978). Octopus: Physiology and behavior of an advanced invertebrate. London, UK: Chapman and Hall.

Wiener, J., Shettleworth, S., Bingman, V. O., Cheng, K., Healy, S., Jacob, L. F. ... Newcombe, N. S. (2011). Animal navigation: A synthesis. In R. Menzel \& J. Fischer (Eds.), Animal thinking (pp. 51-78). Cambridge, MA: MIT Press.

Williamson, R. \& Chrachri, A. (2004). Cephalopod neural networks. Neurosignals, 13, 87-98.

Withagen, R., DePoel, H. J., Araujo, D. \& Pepping, G. J. (2012). Affordances can invite behavior: Reconsidering the relationship between affordances and agency. New Ideas in Psychology, 30, 250-258.

Wodinsky, J. (1969). Penetration of the shell and feeding on gastropods by Octopus. American Zoologist, 9, 997-1010.

Wood, J. B., Maynard, A. E., Lawlor, A. G., Sawyer, E. K., Simmons, D. M., Pennoyer, K. E. \& Derby, C. D. (2010). Caribbean reef squid, Sepioteuthis sepioidea, use ink as a defense against predatory French grunts, Haemulon flavolineatum. Journal of Experimental Marine Biology and Ecology, 388, 20-27.

Zarrella, I., Ponte, G., Baldascino, E. \& Fiorito, G. (2016). Learning and memory in Octopus vulgaris: A case of biological plasticity. Current Opinion in Neurobiology, 35, 74-79.

Zullo, L., Sumbre, G., Agnsola, C., Flash, T. \& Hochner, B. (2009). Nonsomatotopic organization of the higher motor centers in Octopus. Current Biology, 19, 1632-1636. 